\title{
EVALUATING THE MOISTURE CONDITIONS IN THE FRACTURED ROCK AT YUCCA MOUNTAIN: THE IMPACT OF NATURAL CONVECTION PROCESSES IN HEATED EMPLACEMENT DRIFTS
}

\author{
J. T. Birkholzer ${ }^{1}$, S. W. Webb ${ }^{2}$, N. Halecky ${ }^{1,3}$, P. F. Peterson ${ }^{3}$, G. S. Bodvarsson ${ }^{1}$ \\ ${ }^{1}$ Ernest Orlando Lawrence Berkeley National Laboratory \\ ${ }^{2}$ Sandia National Laboratories \\ ${ }^{3}$ University of California at Berkeley
}

\author{
Corresponding Author: \\ J.T. Birkholzer \\ Ernest Orlando Lawrence Berkeley National Laboratory \\ Earth Sciences Division \\ 1 Cyclotron Road, MS 90-1116, Berkeley CA 94720 USA \\ phone (510) 486-7134, email: jtbirkholzer@lbl.gov
}

\begin{abstract}
The energy output of the high-level radioactive waste to be emplaced in the proposed geologic repository at Yucca Mountain, Nevada, will strongly affect the thermal-hydrological $\mathrm{TH})$ conditions in the near-drift fractured rock. Heating of rock water to above-boiling conditions will induce large water saturation changes and flux perturbations close to the waste emplacement tunnels (drifts) that will last several thousand years. Understanding these perturbations is important for the performance of the repository, because they could increase, for example, the amount of formation water seeping into the open drifts and contacting waste packages. Recent computational fluid dynamics (CFD) analysis has demonstrated that the drifts will act as important conduits for gas flows driven by natural convection. As a result, vapor generated from boiling of formation water near elevated-temperature sections of the drifts may effectively be transported to cooler end sections (where no waste is emplaced), would condense there, and subsequently drain into underlying rock units. Thus, natural convection processes have great potential for reducing the near-drift moisture content in heated drift sections, which has positive ramifications for repository performance. To study these processes, we have developed a new simulation method that couples existing tools for simulating TH conditions in the fractured formation with modules that approximate natural convection and evaporation conditions in heated emplacement drifts. The new method is applied to evaluate the future TH conditions at Yucca Mountain in a three-dimensional model domain comprising a representative emplacement drift and the surrounding fractured rock.
\end{abstract}




\section{INTRODUCTION}

In the last few decades, extensive scientific investigations have been conducted at Yucca Mountain, Nevada, to explore whether the site is suitable for geologic disposal of high-level radioactive waste (Bodvarsson et al., 1999). If constructed, the repository will be located in partially saturated fractured rock several hundred meters above the groundwater table, at a depth of about $300 \mathrm{~m}$ below the ground surface. In the current design, cylindrical waste canisters will be distributed along horizontal tunnels of $5.5 \mathrm{~m}$ diameter and several hundred meters in length. The radioactive decay will produce a heat flux that will significantly change the thermal and hydrological environment at Yucca Mountain, affecting both the host rock and the conditions within the tunnels. It is expected that this thermal perturbation will prevail for thousands of years after waste emplacement (e.g., Buscheck et al., 2002; Haukwa et al., 2003). For some period, temperatures within and near emplacement drifts will be above boiling, which will give rise to complex multiphase flow and heat-transfer processes. Pore-water vaporization and subsequent condensation will lead to a large saturation and flux redistribution in the fractured rock. Vapor will also enter the emplacement drifts, thereby increasing the relative humidity near the waste packages (see discussion in Section 2.2). Understanding and predicting these changes-in both the natural system as well as in the drifts-is essential for evaluating the future performance of the repository in terms of canister corrosion and radionuclide containment.

The thermally driven flow processes to be expected in the fractured rock at Yucca Mountain have been investigated in various modeling studies (e.g., Pruess et al., 1990a, 1990b; Haukwa et al. 1999; Buscheck et al. 2002; Haukwa et al., 2003; Birkholzer et al., 2004). The methodology used in these predictive studies (e.g., use of the continuum approach, dual-permeability concept) was validated against the TH response of large in situ heater tests conducted at the proposed repository site (Tsang and Birkholzer, 1999; Birkholzer and Tsang, 2000; Mukhopadhyay and Tsang, 2002; Mukhopadhyay and Tsang, 2003). Model conceptualizations have mainly focused on large-scale average behavior for the entire repository (e.g., Haukwa et al., 1999) and on local domains featuring individual emplacement drifts with two-dimensional representations (e.g., Haukwa et al., 2003, Birkholzer et al., 2004), or have combined these two approaches in a multiscale treatment (Buscheck et al., 2002). All these models assume that gas flow processes along emplacement drifts can be neglected, either because individual drifts were not represented at all or were treated as closed systems without axial flow and transport components. As a result, 
the models predict that the majority of the vapor produced from boiling/evaporation of formation water remains in the fractured rock. In reality, there may be considerable vapor transport from the fractured formation into the emplacement drifts. The importance of this vapor transfer depends largely on the transport mechanism that moves vapor away from the vapor-producing sections to the cold ends of the drift.

Recent CFD simulations of gas flows within emplacement drifts suggest that the in-drift conditions at Yucca Mountain will be heavily affected by heat-induced natural convection (Webb et al., 2003; Dalvit-Dunn et al., 2004; Webb and Reed, 2004; Webb and Itamura, 2004). Large-scale convection cells were predicted to form inside the drifts in the axial direction, with gas velocities on the order of centimeters per second. Such large-scale axial circulation patterns would provide an effective mechanism for vapor transport from heated to unheated drift sections. Based on detailed CFD simulations, Webb and Itamura (2004) approximated the simulated circulation flow patterns as an axial binary diffusion process (counter-diffusion of vapor and air), using effective mass-dispersion coefficients directly estimated from the CFD flow fields. To estimate the magnitude of vapor transport, the calculated dispersion coefficients were used as input to a semi-analytical model for one-dimensional heat and vapor transport along drifts (Webb and Reed, 2004). The analysis demonstrated the importance of convective mixing between vapor-rich (hot) and vapor-poor (cool) drift sections. However, while the in-drift processes were captured in detail, the presence of the fractured rock was approximated using precalculated boundary conditions, thus neglecting the important feedback between the in-drift and the fractured-rock TH conditions. An alternative methodology with a more sophisticated treatment of the near-drift formation was developed by Danko and Bahrami (2003, 2004), using an iterative procedure to decouple the drift and rock-mass formulations. Danko and Bahrami (2003, 2004) applied their model to evaluate the efficiency of ventilation in emplacement tunnels.

In this paper, we describe a new coupled simulation method that simultaneously handles (1) the flow and energy transport processes in the fractured rock; (2) the flow and energy transport processes in the open drifts; and (3) the heat, fluid, and gas exchanges at the interface between the rock formation and the cavity. The model concepts used for the partially saturated flow and heat transport in the fractured formation are based on existing models as described, for example, in Haukwa et al. (2003) and Birkholzer et al. (2004). Following Webb and Itamura (2004), in-drift convection is approximated as a binary diffusion process, with effective 
dispersion coefficients estimated from supporting CFD analyses. Mass and heat transfer between the formation and the drift are approximated by empirical boundary-layer correlations (Kuehn and Goldstein, 1976, 1978; Raithby and Hollands, 1985), based on a methodology developed in Webb and Reed (2004). The governing equations for the integrated drift and rock-mass model are solved in a fully coupled, noniterative manner, ensuring consistency between the thermalhydrological conditions in the fractured rock and those in the open drift.

Our new, coupled simulation method is applied to study the future TH conditions at Yucca Mountain in a three-dimensional model domain comprising a representative emplacement drift and the surrounding fractured rock. Our main objective is to better understand how natural convection in drifts affects the near-drift TH processes, particularly with respect to the saturation changes and flux perturbations in response to the elevated temperatures. Sensitivity studies are conducted using two sets of effective dispersion coefficients, corresponding to different degrees of convective circulation within the open tunnels. Transient simulations are performed for the first 5,000 years after waste emplacement, comprising a short-term "hot" period, where drift and rock temperatures are above boiling, as well as long-term "cool” period, where drift and rock temperatures return back to ambient values. Model results are compared with simulations in which the effect of natural convection is neglected, and conclusions are drawn with respect to the impact of our findings on repository performance. 


\section{MODELING APPROACH}

\section{1 Relevant Yucca Mountain Design Features}

The current DOE design for the geologic repository at Yucca Mountain envisions emplacement of waste canisters in a large number of parallel drifts spaced $81 \mathrm{~m}$ apart, as schematically illustrated in Figure 1. Typically, these drifts have an emplacement section about $600 \mathrm{~m}$ long followed by unheated end sections (turnout sections), which can be as long as $100 \mathrm{~m}$ or more (design norm is $97 \mathrm{~m}$ ). In contrast to the access drifts and shafts, which will be backfilled with crushed tuff material, the emplacement drifts including their end sections will remain open, allowing for natural convection and turbulent mixing to occur. The cylindrical waste canisters, about $5 \mathrm{~m}$ long and between $1.75 \mathrm{~m}$ and $2.11 \mathrm{~m}$ in diameter, are distributed horizontally along the drifts, with an axial distance of $0.1 \mathrm{~m}$ between them. The canisters sit on support pallets placed on the drift invert, which will be made of crushed tuff. A drip shield covers the waste packages and protects them from rock fall and water seepage.

Current design estimates for waste package loading at Yucca Mountain assume an initial heat load of the radioactive waste of $1.45 \mathrm{~kW}$ per meter drift length; this value represents the average heat load for different waste packages (BSC, 2003). The initial heat load decreases exponentially with time as a result of radioactive decay. During a 50-year preclosure period following emplacement, forced ventilation will remove the majority of the heat from the repository, ensuring that the temperature increase is moderate and access to the drifts is still possible. However, as soon as forced ventilation is turned off (postclosure period), temperatures within the drifts and in the surrounding rock will rise significantly to above-boiling conditions and remain there for several hundred years, causing a significant redistribution of pore water (e.g., Buscheck et al., 2002; Birkholzer et al., 2004). With time and declining heat output, temperatures will eventually start to decrease, but will continue to be elevated from ambient for thousands of years, because of the long half-life of the radionuclides. 


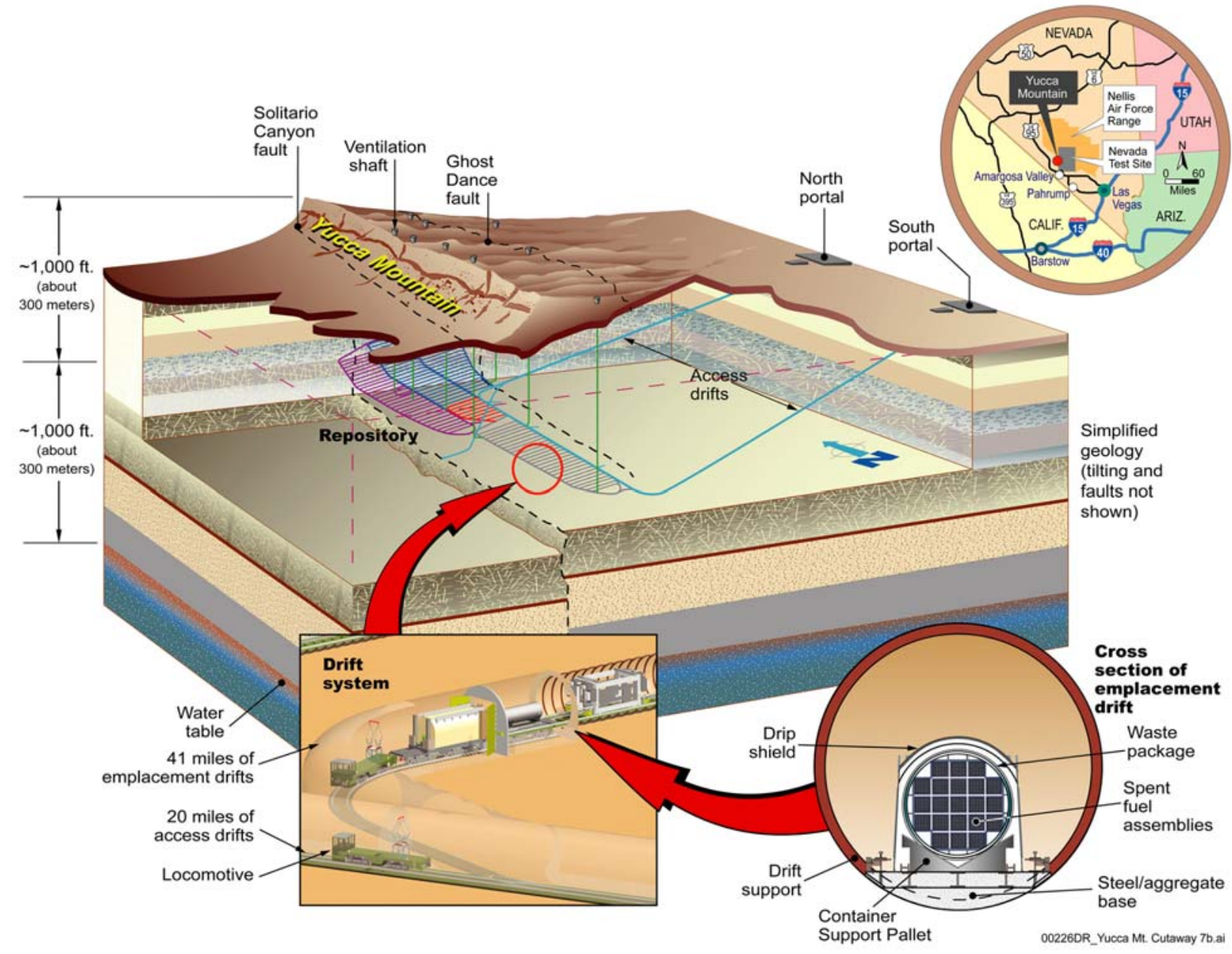

Figure 1: Schematic of emplacement design at Yucca Mountain

\section{2 TH Processes Expected Near and Within Heated Emplacement Drifts}

The following gives a brief overview of the heat-induced flow and transport processes expected at Yucca Mountain.

\section{$\underline{\text { Fractured Rock Mass }}$}

The heat emanating from the waste packages will be effectively transferred to the drift walls and into the near-drift formation (Birkholzer et al., 2004). Thermal radiation dominates the heat transport within the drift, while heat conduction is most important in the fractured rock. As the partially saturated formation near the drifts heats up, the initially mostly stagnant pore water in the matrix will become mobile through boiling (see Figure 2a). Vaporization will create a pressure increase, which will drive the vapor into the highly permeable fractures that are present 
in abundance in the repository rock layers. The vapor will then move away from the boiling region through the fracture network, mostly driven by the gas pressure gradient, and a hot dryout zone (no liquid water present) will develop close to the heated drift sections (e.g., Pruess et al., 1990a, 1990b; Buscheck et al., 2002; Birkholzer et al., 2004). It can be assumed that the gas pressure within the drifts will remain at atmospheric conditions, because any pressure increase would vanish in axial direction owing to the good communication of the drift with other tunnels and large rock volumes. Thus, a portion of the vapor produced in the boiling rock region will be driven back towards the drifts, thereby increasing the vapor concentration in the heated drift sections. The remaining portion moves away in radial direction towards cooler rock regions, where the vapor eventually condenses on the fracture walls. Such condensation may give rise to elevated liquid fluxes in the fractured rock, a potential concern for performance assessment because of the potential for thermal seepage. At later stages, when temperatures have decreased below boiling, the rock mass near the drifts will gradually rewet (Figure 2b). For drifts with average temperature conditions, rewetting will occur roughly a few hundred years after boiling has ceased, a time period at which natural convection processes within the drifts are still important.

\section{Emplacement Drifts}

The axial and radial temperature gradients expected in emplacement drifts will cause natural convection processes that can significantly affect the moisture conditions within the drifts (Webb and Reed, 2004; Webb and Itamura, 2004). Large-scale circulation patterns will form along the drifts as a result of axial temperature and concentration gradients, causing effective axial mixing (Figure 2). In addition, transverse natural convection flows will occur due to the temperature difference between the radioactive waste and the drift wall, generating small-scale turbulence and turbulent mixing that can further enhance axial mass transport. If sufficient in size and magnitude, these large-scale axial circulation patterns and additional turbulent mixing from transverse natural convection can reduce the overall moisture content in heated drift sections because of the presence of unheated drift (turnout) sections. Principles of thermodynamics suggest that the maximum amount of vapor that can be present in an air-vapor mixture decreases with declining temperature. Thus, the warm vapor-rich gases moving from heated drift sections toward the drift turnouts—caused by natural convection processes — will be depleted of most of their vapor content by condensation on cooler rock surfaces. (As shown in Figure 2, the condensate will drain away from the repository into underlying rock units.) At the same time, 
vapor-poor gas will circulate back towards the emplacement sections of the drifts, thereby reducing the vapor concentration and the relative humidity in these areas. This effect, in turn, will generate a concentration gradient between the fractured rock and the in-drift environment, causing diffusive vapor transport from the formation into the drift, in addition to the convective vapor transport caused by the formation pressure increase during boiling.

\section{(a) Boiling Phase: Heated Drift Section Above Boiling Temperature}

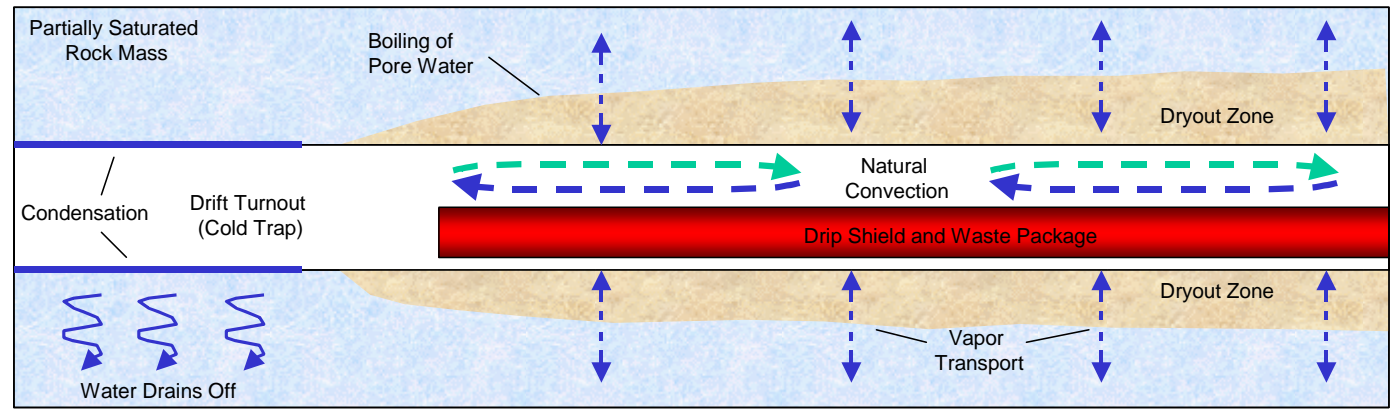

(b) Sub-Boiling Phase: Heated Drift Section Below Boiling Temperature

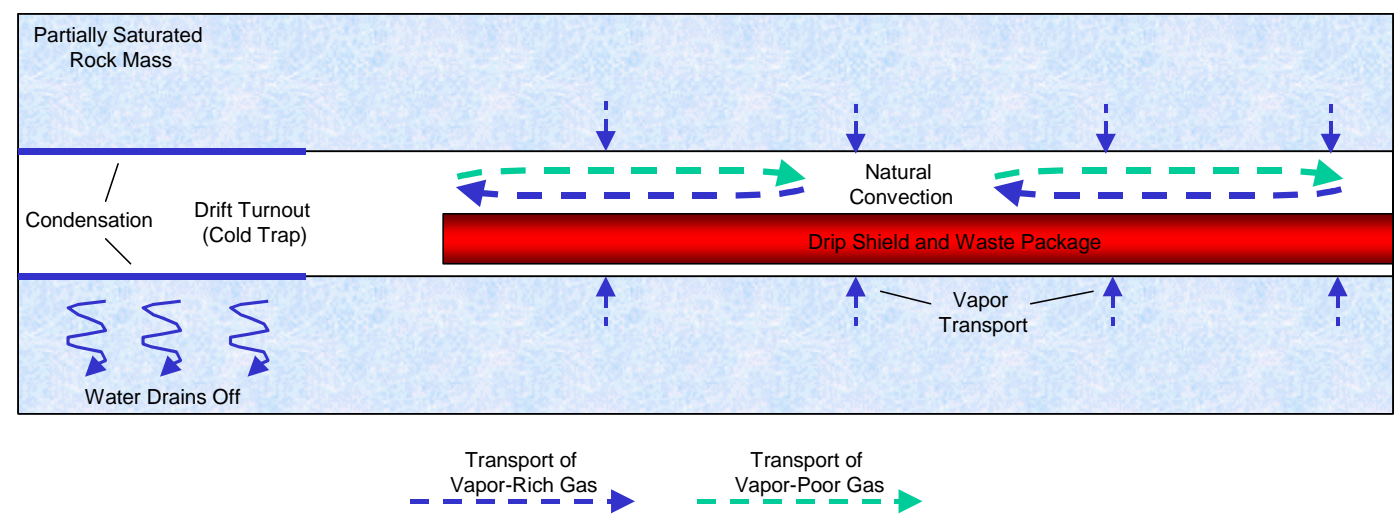

Figure 2: Schematic of expected TH processes along emplacement drift during boiling conditions. The figure depicts part of a drift with emplacement and end sections (modified from Webb and Reed, 2004).

\subsection{Conceptual Model for TH Processes in Fractured Rock}

In this section, we shall briefly review the conceptual framework for simulating the $\mathrm{TH}$ conditions in the fractured rock, which is adopted from existing TH models for Yucca Mountain (e.g., Buscheck et al., 2003; Haukwa et al., 2003; Birkholzer et al., 2004). The relevant TH processes in the heated rock mass are the convective and diffusive movement of gaseous and liquid phases of components water and air (under pressure, viscous, capillary, and gravity forces); transport of latent and sensible heat; phase transition between liquid and vapor; and 
vapor pressure lowering (Pruess et al., 1999). The fractured rock is described using a dual permeability concept, assuming two separate but interacting continua that overlap with each other in space. One continuum describes flow and transport in the fracture network; the other describes flow and transport in the matrix (Doughty, 1999). Dual permeability concepts assume that there are two elementary volumes at each spatial location representing the fractures and the matrix, respectively, each having a pressure, saturation, temperature, or vapor concentration value. Global flow and transport occur within both the fracture continuum and the matrix continuum, while local fracture-matrix interaction occurs between the two continua as a result of local differences in TH conditions. Thus, disequilibrium conditions between fractures and matrix and the corresponding mass and heat transfer can be efficiently modeled without explicitly accounting for all individual fractures and matrix blocks.

\section{2 Conceptual Model for In-Drift TH Processes and Coupling with Fractured Rock}

In principle, the mass and heat transport processes occurring in an open drift could be modeled with a CFD simulator that would solve the mass, momentum, and energy conservation equations, including their turbulent contributions (e.g., Webb et al., 2003; Dalvit-Dunn et al., 2004; Webb and Reed, 2004; Webb and Itamura, 2004). However, solving the turbulent velocity fields expected in heated drift sections would require fine spatial and temporal resolution. Not only would this result in highly time-consuming simulation runs, but would also necessitate complex coupling approaches, because of the large discretization disparities between the drift and the fractured rock. In this work, we are not interested in a detailed representation of in-drift gas flow processes. Rather, we are interested in the global large-scale vapor transport in the drift and the impact that in-drift natural convection has on the TH conditions in the near-drift fractured rock. This requires a reasonable approximation of axial vapor transport along the drifts, but does not require detailed resolution of convective flow patterns. Thus, for the purpose of this study, we follow the methodology described in Webb and Itamura (2004), and assume that the axial transport of vapor and air can be characterized by a binary diffusion process of the airvapor mixture, using effective mass dispersion coefficients calculated from complementary CFD flow field simulations.

To estimate effective mass dispersion coefficients for convective mixing, Webb and Itamura (2004) conducted detailed CFD simulations for a $70 \mathrm{~m}$ long section of a representative emplacement drift at Yucca Mountain. Two simulation cases were considered, uaing different 
temperature boundary conditions to account for the three-dimensional nature of the repository temperatures: One case assumed a uniform boundary temperature along the drift section, representing a drift in the repository center. The other case assumed a temperature gradient of a few degrees centigrade between the two ends of the drift section, representing a drift at the edge of the repository. The effective mass dispersion coefficients calculated for these cases - at 300, 1,000, and 3,000 years after emplacement—are summarized in Table 1. Higher dispersion coefficients are obtained for the temperature-gradient case, reflecting the larger circulation patterns observed in the CFD simulations. In both cases, the resulting coefficients are considerably larger than the standard molecular diffusion coefficient of a vapor-air mixture of $2 \times 10^{-5} \mathrm{~m}^{2} / \mathrm{s}$. As pointed out in Webb and Reed (2004), the two cases provide first-order estimates for analyzing the impact of convective mixing in emplacement drifts. Various simplifying model assumptions were made that suggest that the derived coefficients are likely low. Note for example that the CFD simulations did not include buoyancy forces induced by the density difference between vapor and air, since a single component gas phase was assumed.

Table 1: Effective mass dispersion coefficients ( $\left.\mathrm{m}^{2} / \mathrm{s}\right)$ given in Webb and Itamura (2004)

\begin{tabular}{|l|c|c|c|}
\hline Cases & 300 yrs & 1000 yrs & 3000 yrs \\
\hline $\begin{array}{l}\text { Case 1: Temperature Gradient } \\
\text { (Strong convective mixing) }\end{array}$ & 0.1 & 0.1 & 0.1 \\
\hline $\begin{array}{l}\text { Case 2: No Temperature Gradient } \\
\text { (Moderate convective mixing) }\end{array}$ & 0.008 & 0.004 & 0.004 \\
\hline
\end{tabular}

We use the two sets of effective mass dispersion coefficients in a parametric study evaluating the potential impact of natural convection on the TH conditions in the near-drift fractured rock. By approximating natural convection as a binary diffusion process, the in-drift heat and fluid flow processes can be simulated with standard methodologies applied for Darcy-type flow and transport. For the presented study, we implemented a new drift simulation module into TOUGH2, a general-purpose simulator for coupled fluid and heat flow of multiphase, multicomponent fluid mixtures in porous and fractured media (Pruess, 1987; Pruess et al., 1999). In addition to various other applications, TOUGH2 has been widely used for simulating TH processes in the fractured rock at Yucca Mountain (e.g., Haukwa et al., 2003; Birkholzer et al., 2004). The new version of TOUGH2 is applied to simultaneously solve for heat and fluid flow within the drift and in the surrounding rock mass, with the drift represented as a solution 
subdomain that requires certain modifications and parameter specifications. These are listed as follows:

(1) All drift elements representing the open enclosure (see Figure 3) are assigned the effective mass dispersion coefficients developed by Webb and Itamura (2004). For the transient TH simulations, the coefficients determined at 300 years are used for the postclosure period up to 600 years after emplacement, the coefficients determined at 1,000 years are used for the period from 600 to 2,000 years, and the coefficients determined at 3,000 years are used for the remainder of the simulation period up to 5,000 years (see Table 1). The coefficients are assumed to be uniform over the entire length of the drift. For simplification, we furthermore assume that the radial dispersion coefficients are identical to the axial ones.

(2) Drift elements representing the open enclosure are assigned the thermophysical properties (density, thermal conductivity, heat capacity) of the vapor-air mixture at prevailing temperatures and pressures.

(3) Drift elements representing the open enclosure are assigned Darcy-type permeability values large enough to ensure that the pressure in the emplacement drifts remains close to atmospheric throughout the boiling period. In other words, the drift pressure response to the boiling-induced pressure increase in the fractured formation should be negligibly small. After some sensitivity testing, this was achieved by using a permeability value equal to or larger than $10^{-8} \mathrm{~m}^{2}$, about four orders of magnitude larger than the permeability of the fractured rock mass. (We also ensured that the convective gas flow velocities simulated using these permeability values are several orders of magnitude smaller than the natural convection flows modeled in the CFD simulations by Webb and Itamura (2004). This is important because the impact of natural convection is already accounted for as a binary diffusion process.)

(4) The waste package, the drip shield, and the small air space between them are treated as a lumped entity in the simulation runs with equivalent thermal properties. Thus, the flow and transport processes occurring under the drip shield are neglected in this study. For simplicity, we use the term "waste package” for the lumped waste package, air gap, and drip shield unit.

(5) Thermal radiation is accounted for using a diffuse gray-body approximation with the hotter waste package surfaces emitting and the cooler drift wall and invert surfaces receiving. The Stefan-Boltzmann law with the appropriate view factors calculated with Hottel's method 
(Siegel and Howell, 1972) allows for a detailed representation of the surface-to-surface heat transfer. Wall-to-wall radiation is neglected.

(6) The heat and mass transfer between the gas flow in the drifts and the confining surfaces is calculated from empirical boundary-layer correlations given in the literature. It is well known that such transfer is affected by the presence of a surficial fluid boundary layer, where the motion of particles is retarded compared to the free stream velocity (e.g., Incropera and DeWitt, 2002). Extensive experimental and theoretical work has been conducted in the past to study and describe these processes, and various empirical correlations have been developed for heat and mass transfer through the boundary layers forming in simplified geometries. Following Webb and Reed (2004), the correlations used in this study are based on work by Kuehn and Goldstein (1976 and 1978), for free convection in the annular space between long horizontal eccentric cylinder, and by Raithby and Hollands (1985), for free convection between long horizontal upward-facing plates. Using these correlations, the new version of TOUGH2 calculates the heat transfer between the open drift and the confining bodies as a function of empirical heat-transfer coefficients and the local temperature gradient. Diffusive mass transfer is calculated from similar correlations, using an empirical masstransfer coefficient and the local vapor concentration gradient. This is done for heat transfer between the waste package and the open drift, for heat and mass transfer between the open drift and rock mass (for both fracture and matrix continua), and for heat and mass transfer between the open drift and the invert. Further details on the methodology are given in Webb and Reed (2004).

As discussed in Ghezzehei et al. (2004), the diffusive mass transfer across the drift wall boundary will be different when a continuous liquid film develops on the surface of the fractured rock. In this case, one would have to solve for evaporation from a free water surface, rather than calculating the diffusive exchange between the gas phase in the drift and the gas phase in partially saturated rock mass. However, the formation of liquid films on the drift walls in the heated drift sections is only expected for late time periods when rewetting of the near-drift rock mass has occurred, and only for unusually high percolation fluxes arriving at the drifts such that pore water would overcome the retaining capillary forces. This may be locally possible, as a result of infiltration variability and flow heterogeneity, but does not represent average behavior over long drift sections. Therefore, we neglect the possibility of liquid films forming on the walls of heated drift sections in this work. 


\subsection{Model Geometry}

Three-dimensional simulation runs are performed for a representative emplacement drift chosen in one of the southern panels of the repository (Figure 3). In the vertical direction (z-direction), the model comprises the entire unsaturated zone, using the ground surface as the upper model boundary and the groundwater table as the lower model boundary. Two symmetry assumptions are used to increase the computational efficiency of the simulation runs. In axial drift direction (y-direction), symmetry allows for reducing the model to half of the drift length (plus sufficient volumes of fractured rock beyond the end of the drift to provide adequate boundary conditions). Thus, the simulated drift comprises half of the typical emplacement section length (300 m) followed by an unheated section away from the symmetry axis, here assumed to be $90 \mathrm{~m}$ long. Following the grid design developed by Spycher et al. (2003), symmetry assumptions can also be used to reduce the model domain in the x-direction, perpendicular to the drift axis. The current repository design of parallel drifts can be represented as a series of symmetrical, identical half-drift domains with vertical no-flow boundaries between them. Thus, the numerical mesh can be reduced to a lateral width of $40.5 \mathrm{~m}$, extending from the drift center to the midpoint between drifts. The model geometry is further simplified by neglecting the curvature of the drift turnout and by assuming strictly horizontal top and bottom model boundaries.

The numerical grid used in the simulations is shown in Figure 3 on a vertical cross section orthogonal to the drift axis. With the focus on in-drift and near-drift conditions, it is important to represent the drift and its vicinity with a refined discretization. In this cross section, the drift domain comprises one finite volume for the waste package (for the lumped waste package, air gap, and drip shield unit), one finite volume for the invert, and 18 finite volumes for the annulus. Remember that in the rock-mass domain, there are two overlapping continua for the fractures and the matrix blocks, respectively, with identical discretizations. In the third dimension (along the drift axis), the numerical grid comprises 28 vertical slices of varying thickness, ranging from $5 \mathrm{~m}$ to more than $100 \mathrm{~m}$. The entire three-dimensional grid comprises about 10,000 finite volumes with about 35,000 connections between them. 


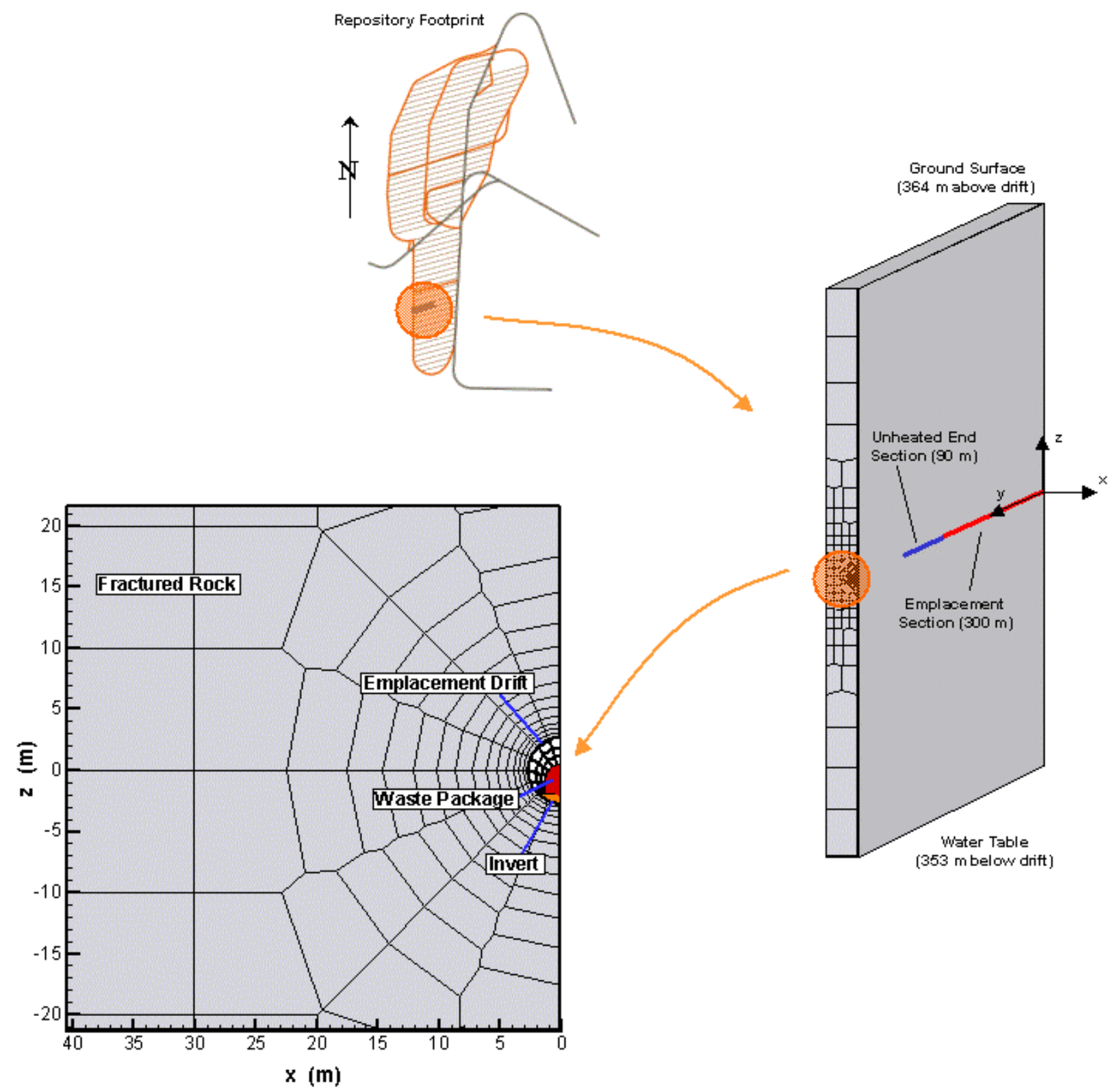

Figure 3. Schematic showing the geometry of the three-dimensional model domain (not to scale). Closeup view shows discretization of drift and drift vicinity.

\subsection{Model Boundary Conditions}

Both the top and bottom boundaries of the model domain are far enough away from the repository units so as not to be affected by the thermal input. (Repository units are those geologic units at Yucca Mountain in which the emplacement drifts will reside.) Accordingly, these boundaries are assigned constant Dirichlet-type conditions for temperature and pressure, with 
boundary values based on the geothermal gradient and gas-static initial pressure variation with depth. Surface infiltration is modeled by imposing uniform percolation flux values that vary with time. Consistent with future climate and infiltration analyses for the Yucca Mountain, the model considers three long-term climate periods with constant percolation: the present-day climate (up to 600 years from emplacement of waste), the monsoon climate (600-2,000 years), and the glacial transition climate (more than 2,000 years). During these periods, the imposed average percolation fluxes used in this work are 6, 16, and $25 \mathrm{~mm} / \mathrm{yr}$, respectively, representing average infiltration conditions. The groundwater table at the bottom of the model domain is modeled as a flat, stable surface saturated with water. All vertical boundaries are no-flow.

A Dirichlet-type boundary condition is also defined just outside the turnout section, where the emplacement drift is connected to the main access drift via a bulkhead door. Assuming good communication to the atmosphere, the main access drift is represented using a fixed gas-pressure value based on the ambient gas pressure at depth. Also fixed are temperature (using the initial geothermal temperature at depth) and vapor concentration (equilibrium vapor pressure at given temperature). These boundary conditions are constant over time; the effect of short-term barometric pumping is ignored. The bulkhead door separating the main access drift from the emplacement drift is modeled as a low-permeability, low-conductivity zone between the respective domains.

The decay heat of the radioactive waste is imposed as a uniform line load to the lumped waste package unit, thus neglecting the variability of thermal output between individual waste packages. As shown in Figure 4, the heat load is time-dependent, exponentially decaying from an initial value of $1.45 \mathrm{~kW}$ per meter drift length. The figure also reflects the considerable heat removal by forced drift ventilation during the first 50 years after emplacement (preclosure period). Similar to previous studies (e.g., Buscheck et al., 2002; Birkholzer et al., 2004), forced drift ventilation is not explicitly modeled in our simulation. Rather, the heat losses by forced drift ventilation are considered by reducing the effective heat output in the simulation to about $14 \%$ of its original value. Design estimates for the ventilation system suggest that on average $86.3 \%$ of the decay heat can be removed during the preclosure period (Walsh et al., 2004). 


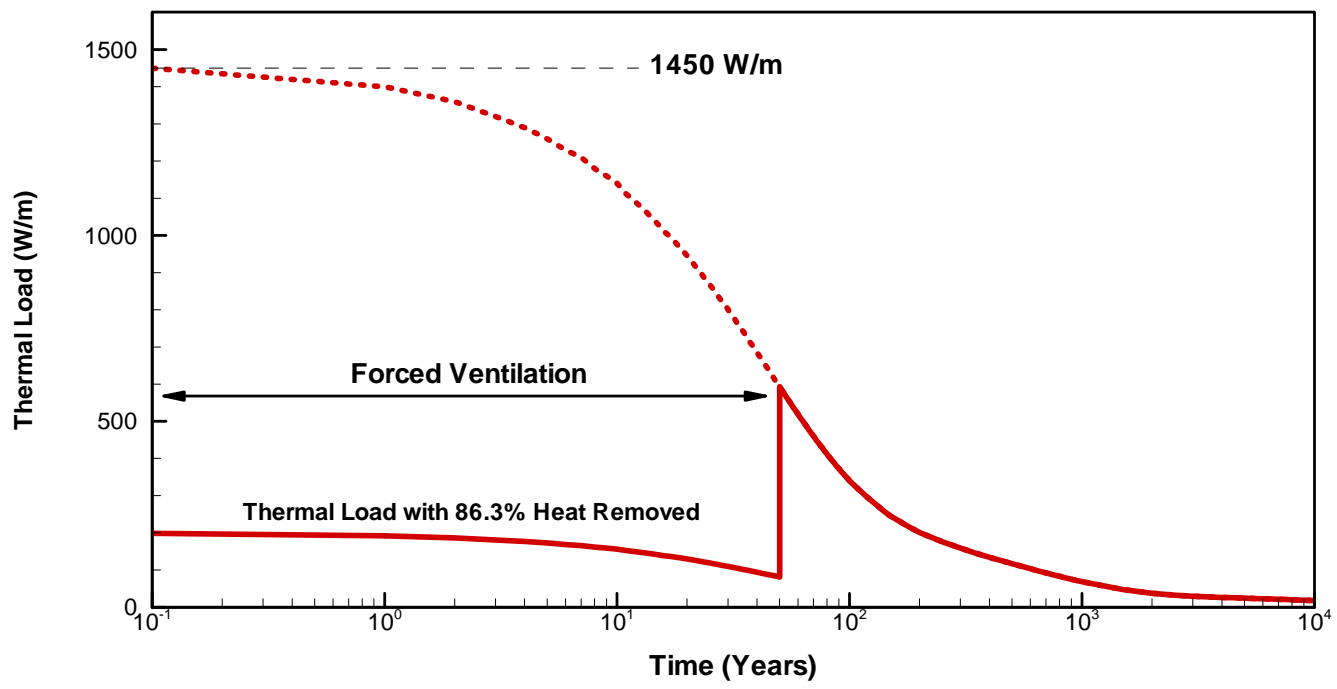

Figure 4. Thermal load as a function of time. Time zero represents the time of waste emplacement.

\subsection{Rock Mass and Drift Properties}

The hydrological and thermal properties (Table 2) assigned to the fractured porous rock are based on property sets compiled in Ghezzehei and Liu (2004). The representative emplacement drift analyzed in our study is situated in the Topopah Spring Tuff lower lithophysal unit, the major host rock unit at Yucca Mountain. Uniform formation properties are used throughout the model domain. We neglect stratigraphic variation above and below the emplacement drifts, which is not relevant for the near-drift TH processes studied in this paper. We also neglect the possible small-scale variability of TH properties.

In-drift elements representing the open annulus outside the drip shield are simulated as a high-permeability porous medium with a porosity of one and zero capillary strength. The basecase permeability in the open annulus is set to $10^{-8} \mathrm{~m}^{2}$. Sensitivity cases were conducted with values of $10^{-7} \mathrm{~m}^{2}$ and $10^{-6} \mathrm{~m}^{2}$, showing small impact on the simulation results. Natural convection is modeled as a binary diffusion process, using the effective mass-dispersion coefficients given in Table 1. The waste package including the area under the drip shield is represented as a solid (nonporous) medium with an effective heat capacity of $394 \mathrm{~J} / \mathrm{kg} / \mathrm{K}$ and a density of $1464 \mathrm{~kg} / \mathrm{m}^{3}$ (averaged over waste package, air gap, and drip shield). The heat load imposed on the waste package is transmitted to the drift wall and invert surfaces (per radiation) as well as into the gas phase in the annulus (per heat transfer across the boundary layer). The invert of the drift, made of crushed tuff material, is represented as a porous medium with large 
permeability and rather weak capillarity. Thermal radiation properties are 0.63 for the emissivity of the drip shield, 0.9 for the emissivity of the drift wall and the invert, and $5.6687 \times 10^{-8}$ $\mathrm{W} / \mathrm{m}^{2} / \mathrm{K}^{4}$ for the Stefan-Boltzmann constant.

Table 2. Hydrogeological and thermal input values of fractured rock mass

Parameter Value

\section{Material Properties}

Matrix Permeability

Matrix Permeability (wall layer)

Matrix Porosity

Matrix Grain Density

Matrix Grain Heat Capacity

Matrix Dry Thermal Conductivity

Matrix Wet Thermal Conductivity

Fracture Permeability
$4.5 \times 10^{-16} \mathrm{~m}^{2}$

$4.5 \times 10^{-15} \mathrm{~m}^{2}$

0.15

$2325 \mathrm{~kg} / \mathrm{m}^{3}$

$985 \mathrm{~J} / \mathrm{kg} / \mathrm{K}$

$1.28 \mathrm{~W} / \mathrm{m} / \mathrm{K}$

$1.89 \mathrm{~W} / \mathrm{m} / \mathrm{K}$

$9.1 \times 10^{-11} \mathrm{~m}^{2}$

Fracture-Matrix Geometry Assumed for Dual-Continuum Formulation

Volume Fraction of Fractures

Fracture-Matrix Interface Area

Representative Distance between Fracture and Matrix Blocks

\section{Moisture Retention Curves}

Matrix Van Genuchten Parameter, $\alpha$ Matrix Van Genuchten Parameter, $m$ Matrix Residual Liquid Saturation

Fracture Van Genuchten Parameter, $\alpha$ Fracture Van Genuchten Parameter, $m$

Fracture Residual Liquid Saturation

Power coefficient for active fracture model
0.0097

$9.8 \mathrm{~m}^{2}$ per unit volume of rock

$0.0528 \mathrm{~m}$

Note: Matrix permeability in the wall layer next to the drift is increased by one order of magnitude to account for excavationinduced property changes. The characteristic curves for partially saturated liquid flow utilize the functional forms introduced by van Genuchten (1980), with a slight modification regarding the maximum possible capillary pressure at small saturations. Gas relative permeability is calculated from $\left(1-\mathrm{k}_{\mathrm{r}}\right)$, where $\mathrm{k}_{\mathrm{r}}$ is liquid relative permeability. Following Liu et al. (1998), the same characteristic curves are used for the active fracture model, but saturation of all fractures is replaced by saturation of active actively flowing fractures. The saturation-dependent thermal conductivity in the matrix is interpolated between dry thermal conductivity and wet thermal conductivity as a square-root function of saturation. Thermal conductivity of fractures is calculated from the matrix thermal conductivity multiplied with the volume fraction of fracture continuum. Specifications on fracture-matrix geometry are based on fracture data from Yucca Mountain. 


\section{MODEL APPLICATION AND RESULTS}

Our model simulations studying coupled TH processes in the drifts and the fractured rock mass cover the first 5,000 years after emplacement of radioactive waste. Being interested in the effects of natural convection, we focus on the postclosure period, which follows the forcedventilation preclosure period of 50 years, and run the simulations until the impact of natural convection becomes less important because of decreasing temperatures. Two main simulation cases are considered using two sets of effective dispersion coefficients: Case 1 represents strong convective mixing in emplacement drifts, Case 2 represents moderate convective mixing (see effective dispersion coefficients in Table 1). For comparison, we also study a simulation case where axial transport along the drift is neglected (Case 3). This is achieved by removing all open drift elements from the numerical grid, thus making the drift cavity an impermeable boundary to the fractured rock mass. The only remaining in-drift elements in Case 3 are those representing the lumped waste package units, which are connected to the drift wall to allow for radiative heat transfer.

The initial conditions for the postclosure simulation runs are derived from simplified model simulations for the preclosure period, where forced ventilation removes a significant amount of the decay heat. As pointed out before, the heat losses from forced ventilation are accounted for by reducing the effective heat generation of the radioactive waste according to Figure 4 . The possible impact of forced ventilation on the moisture content in the rock mass is neglected in these simplified initialization runs.

Simulation results for the postclosure period are first provided in the form of temperature profiles along the drift, extracted in a volume element just above the center of the drift. Figure 5 shows different times during the postclosure period-100, 500, 1,000, 2,000, and 5,000 years after emplacement—for Cases 1 (solid lines) and 2 (dashed lines). The differences between the two cases are rather subtle, indicating that the transport of sensible and latent heat with the gas flow in the drift is not very important for the in-drift temperature distribution. Temperatures for the case with strong convective mixing are slightly lower in the heated section and slightly higher in the end section of the drift, a result of the more effective convective heat transport in axial direction. 
Also depicted in Figure 5 is the initial temperature profile at 50 years. The initial temperature profile shows that the temperature rise from decay heat is moderate during the preclosure period, with maximum in-drift temperatures around $50^{\circ} \mathrm{C}$. Soon after forced ventilation ceases, however, the emplacement section of the drift heats up strongly to about $140^{\circ} \mathrm{C}$ at 100 years, which, as will be shown later, causes boiling of pore water and significant flux perturbation in the adjacent rock mass. The heating trend reverses at later stages, when the reduced heat output of the radioactive waste (see Figure 4) results in a gradual temperature decrease. At 500 years, for example, the indrift temperatures have reduced to a few degrees centigrade above boiling along most of the heated section, while a smaller section is already below boiling temperature (which is $96^{\circ} \mathrm{C}$ at the elevation of the site). All temperature profiles, even at 5,000 years after emplacement, remain elevated from ambient temperature and show moderate to strong temperature differences between the heated drift section and the unheated end.

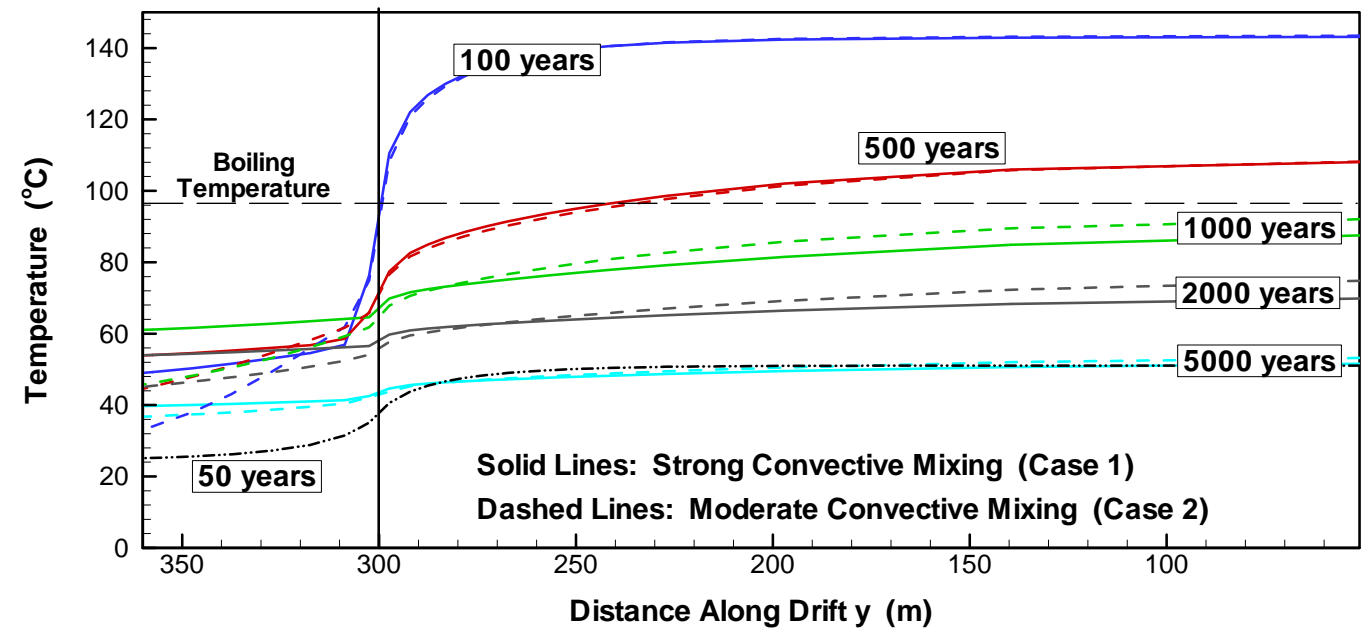

Figure 5. Temperature profiles along emplacement drift, extracted in a volume element just above drift center. The distance along the drift is measured with $y=0$ in the center of the heated section of the drift, the symmetry boundary of the half-drift model. The heated section of the drift ends at $\mathrm{y}=300 \mathrm{~m}$ (indicated by vertical line), followed by a $90 \mathrm{~m}$ long unheated end section.

To evaluate the heat-related moisture redistribution processes, we have plotted in Figures 6 and 7 the TH conditions for a vertical cross section along the drift. We selected the simulation results at 500 years after emplacement, representative of the expected situation towards the end of the superheated period at Yucca Mountain. For better visualization, we focus on the rock mass in the drift vicinity (with vertical extension from $-40 \mathrm{~m} \leq \mathrm{z} \leq 40 \mathrm{~m}$ ), and use a vertical length scale five times the horizontal. We start analyzing Case 1, which features strong convective mixing along the drift (Figure 6). Figure 6a shows temperature and liquid saturation contours as 
well as liquid flux vectors for the fracture continuum and the drift, while Figure $6 \mathrm{~b}$ shows vapor concentration (calculated as the mass fraction of vapor in the gas phase) and liquid saturation contours in the matrix continuum and in the drift. Note that the fracture temperatures are fairly representative of those in the matrix, and that the vapor concentrations in the matrix are a reasonable estimate for those in the fractures. Local exchange of heat and vapor between the matrix and the fractures is quite effective and promotes fast equilibration of thermal perturbation. This finding is typical in densely fractured formations such as the fractured tuff at Yucca Mountain (Doughty, 1999).

Before evaluating heat-related flow and transport processes, we should briefly discuss the ambient (initial) situation in the repository units at Yucca Mountain. At ambient conditions, the matrix pores in the partially saturated formation hold a significant amount of water owing to strong capillary forces, with saturation values of the order of 0.85 . Assuming thermodynamic equilibrium with the matrix, the fractures are essentially drained of water, with the saturation value close to residual. Since the fractures are basically nonconductive at such small saturations and since the matrix has such low permeability, the ambient percolation flux at Yucca Mountain is very small. As pointed out before, a percolation flux of $6 \mathrm{~mm} / \mathrm{yr}$ is assumed for the present hydrological conditions. Prior to heating, the temperature is about $25^{\circ} \mathrm{C}$ at the repository depth, and the gas pressure is close to atmospheric pressure at the elevation of Yucca Mountain. The ambient vapor concentration in the gas phaseis very small, corresponding to a relative humidity of $100 \%$ at $25^{\circ} \mathrm{C}$.

According to our simulation results, these ambient conditions will be strongly altered at 500 years after emplacement by boiling and subsequent condensation of pore water. Both the matrix and the fracture saturation contours in Figure 6 show that a large volume of rock has desaturated in the vicinity of the heated section of the drift, with the region of reduced liquid saturation extending several meters into the formation. The dryout region below the drift is larger than above, where further saturation decrease is somewhat limited by the percolation flux arriving at the boiling zone and the gravity-driven reflux of condensate. Note that desaturation is less common in the matrix continuum compared to the fractures, for two reasons: First, there is significantly more ambient water in matrix pores that would need to boil off. Second, vaporization leads to a pressure increase in the matrix, since the small matrix permeability limits 
the vapor release from the pores. As pressure builds up, the boiling point of water increases, allowing for the presence of liquid water in the matrix at rock temperatures above $96^{\circ} \mathrm{C}$.

Where does the vapor produced from boiling migrate and where does condensation occur? We answer these questions by analyzing regions of elevated saturation (i.e., elevated above the ambient saturation values) as well as by evaluating vapor concentration contours, expressed as vapor mass fraction. Figure $6 \mathrm{~b}$ indicates that the vapor concentration in the gas phase has increased significantly in the heated rock regions, with maximum values above 0.7 a few meters away from the drift. Part of the vapor moves effectively within the highly permeable fractures out into the distant rock mass. As a result, elevated vapor concentrations of 0.3 and more can be seen at distances of $30 \mathrm{~m}$ above and below the heated drift. That condensation of vapor occurs in these cooler rock regions can be inferred from the elevated matrix saturations, which reach maximum values well above 0.9. This saturation increase is caused by condensation of vapor on the fracture walls and subsequent imbibition into the matrix pores. The fracture continuum does not exhibit a corresponding saturation buildup, because the bulk of the condensate drains off immediately as a result of the small fracture capillarity.

The saturation buildup in the fractured rock mass near the unheated end section of the drift is more pronounced, indicating that a significant amount of the vapor produced in the rock mass enters the drift, migrates in axial direction (as a result of circulating gas flows from natural convection), and eventually condenses on the cooler drift wall surfaces. Most of the condensate flows from the drift walls towards the drift bottom through the invert and drains downward in the fracture continuum. As a result, fracture saturation increases strongly below the drift, and significant gravity-driven liquid fluxes occur, driving water away into the underlying formations (Figure 6a). A small fraction of the condensate imbibes from the drift walls into the matrix pores as a result of capillary forces. The impact of such imbibition can be seen in the elevated matrix saturations both above and below the drift end section (Figure 6b). Despite the saturation increase, the liquid fluxes in the matrix are much smaller than those in the fracture continuum. In fact, when plotted on the same length scale, the flux vectors in the matrix are too small to be visible in Figure 6b.

While vapor-rich gas is driven from the heated drift sections towards the unheated drift turnout, vapor-poor gas moves back, thereby reducing the in-drift vapor concentration and 
relative humidity near the heat-producing waste packages. This effect, present along the entire length of the emplacement section, causes a strong vapor concentration gradient between the rock mass and the drift. For example, Figure $6 \mathrm{~b}$ shows that the maximum vapor concentration in the drift is between 0.2 and 0.3 , compared to a maximum value of more than 0.7 in the rock. As a result of this concentration difference, vapor migrates from the heated rock mass into the drift not just by pressure-driven convective flow, but also by diffusion. More detail on the magnitude of the vapor exchange between the fractured rock mass and the drift, as well as on the relative importance of convective versus diffusive transport, will be presented later in this paper.

We may now compare the simulation results for Case 1 in Figure 6 with the simulation results for Case 2 in Figure 7. Whereas the heat-induced moisture redistribution processes are similar in general, Case 2 differs from Case 1 in that the convective mixing between vapor-rich and vapor-poor regions of the drift is less effective. As a result, more vapor remains in the heated rock mass where it is produced, and less vapor migrates from the heated drift section towards the cooler drift turnout. The former is evident in the smaller rock-dryout region above and below the drift, the higher matrix saturation values in the rock-mass condensation zone, and the higher vapor concentrations in both the fractured rock and the heated drift section. The latter shows in the less pronounced fracture and saturation buildup near the drift end section, indicating that less vapor migrates there and condenses on the drift walls. Also, the liquid flux vectors below the drift are considerably smaller in Case 2 compared with Case 1 (the vector scales in both figures are identical).

Note that the vapor concentration contours above and below the drift show a distinct asymmetry in both Figures $6 \mathrm{~b}$ and $7 \mathrm{~b}$, with higher values occurring above the drift. One reason for this asymmetry is the already mentioned asymmetry effect, with less water boiling below the drift than above. More important are the lower temperatures below the drift, a result of the small thermal conductivity of the crushed-tuff invert. Lower temperatures cause a decrease in the saturated vapor pressure, which in turn reduces the maximum possible vapor concentration in the gas phase. 


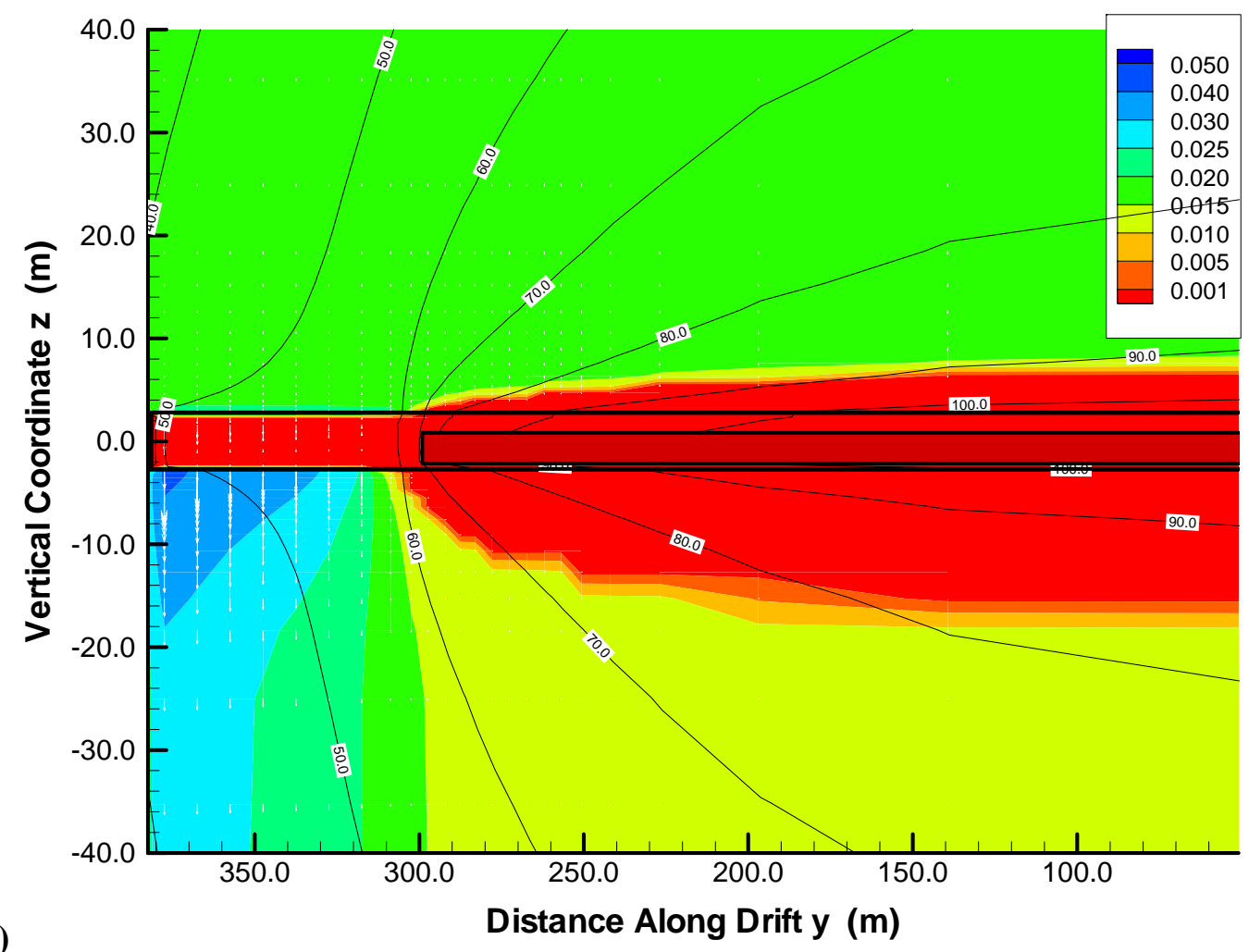

(a)

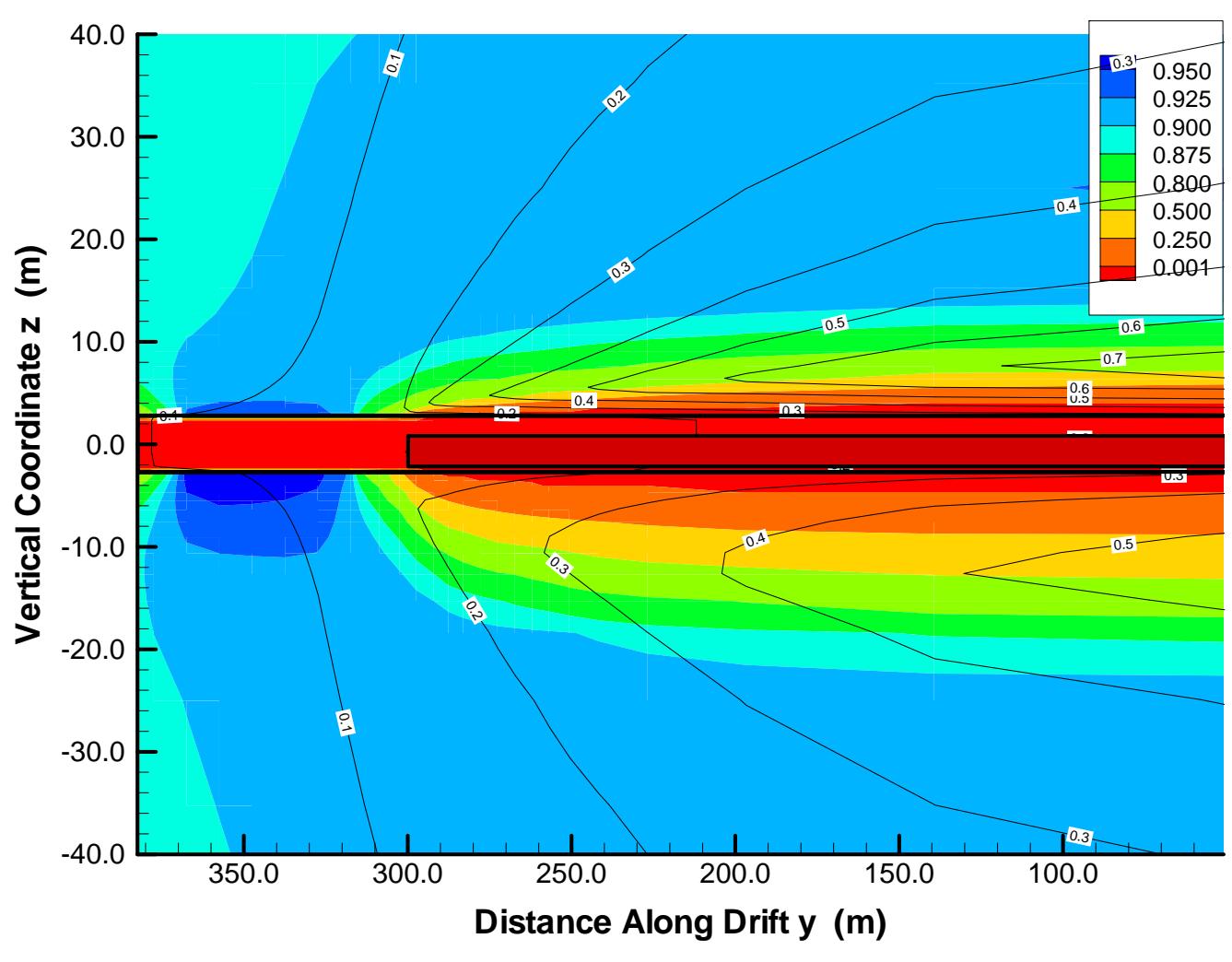

Figure 6. Simulated TH conditions for Case 1 in vertical cross section along drift after 500 years. (a) Colored contours show fracture saturation; contour lines show temperature in the rock mass and in the drift. (b) Colored contours show matrix saturation; contour lines show vapor concentration (vapor mass fraction) in the matrix and in the drift. 


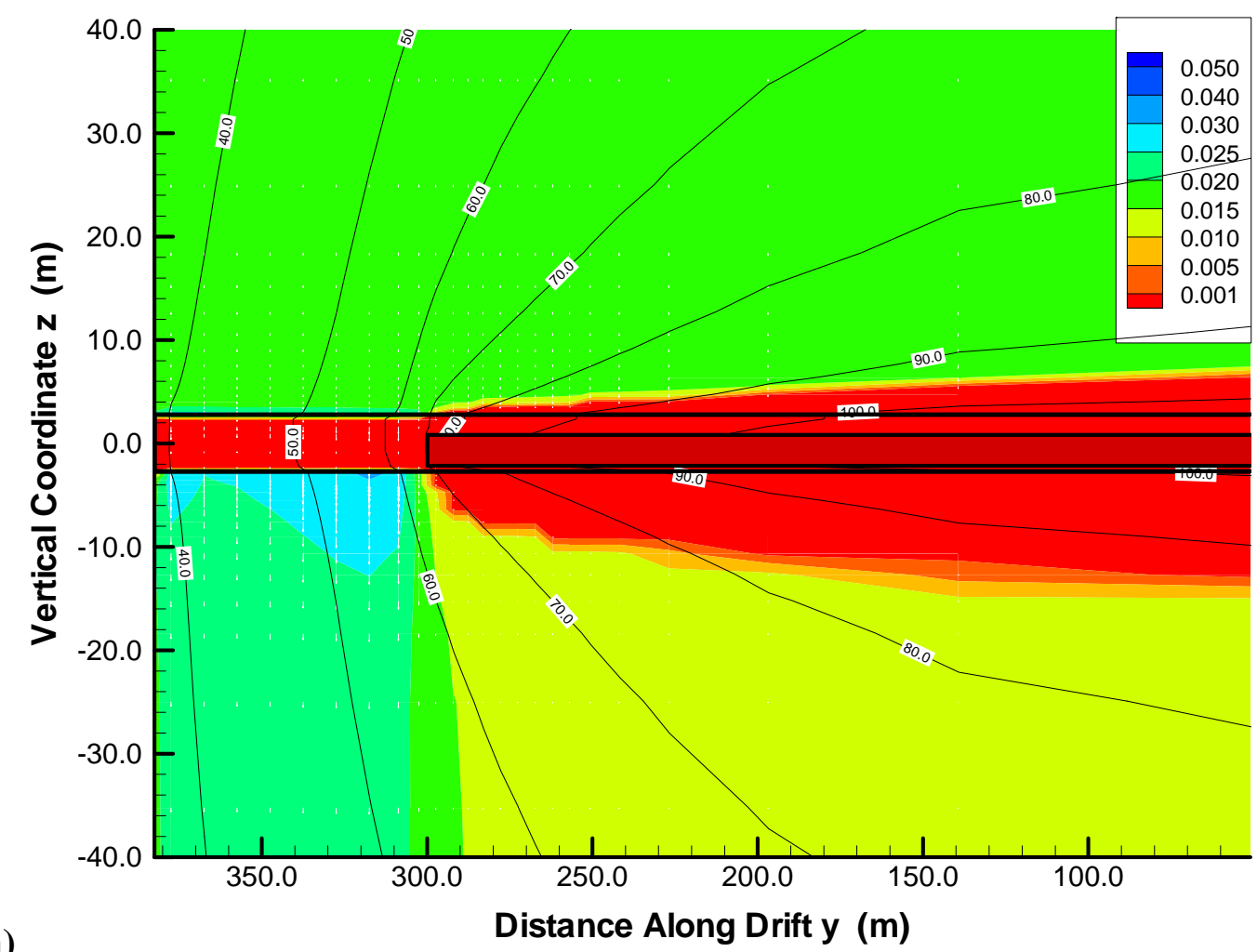

(a)

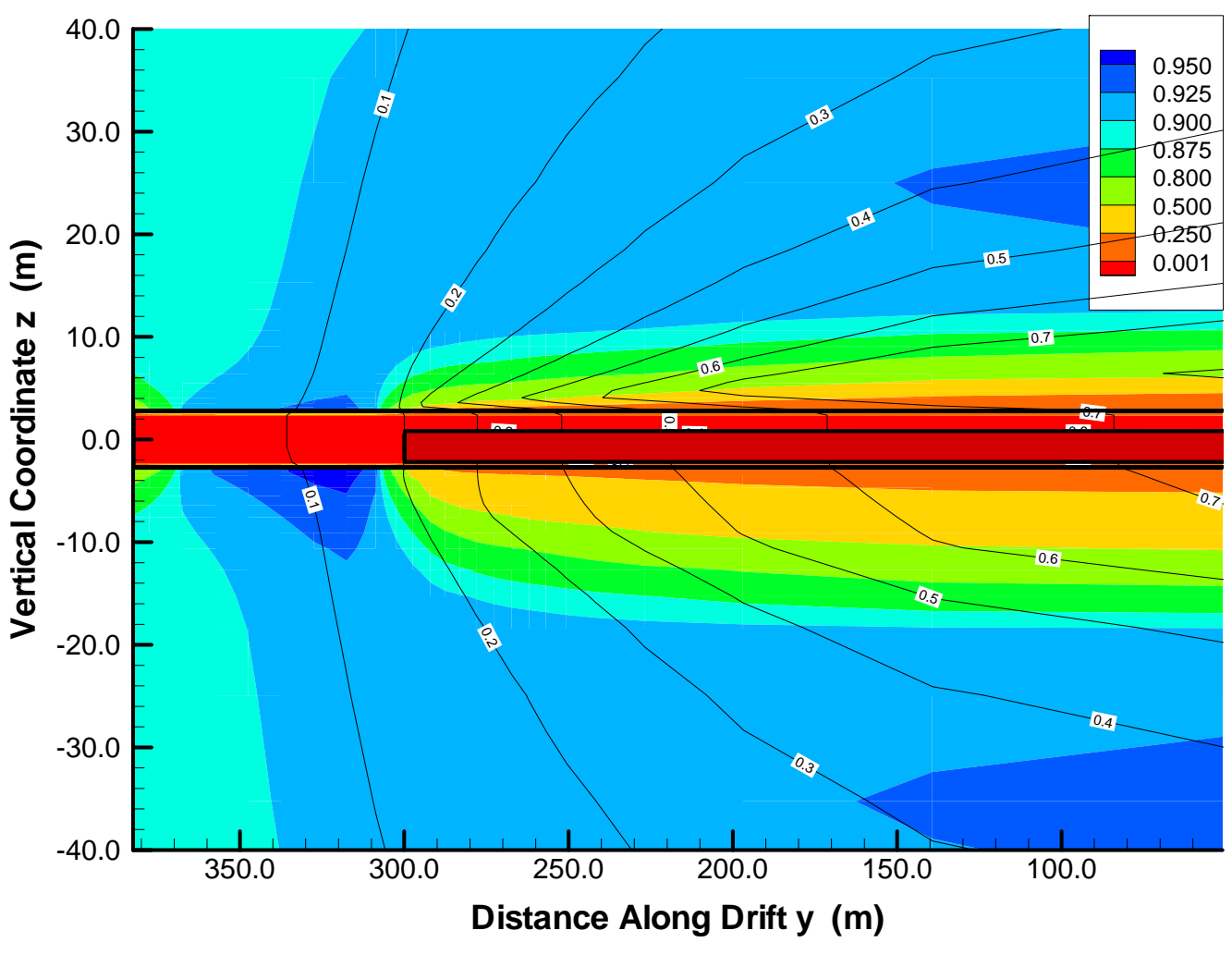

Figure 7. Simulated TH conditions for Case 2 in vertical cross section along drift after 500 years. (a) Colored contours show fracture saturation; contour lines show temperature in the rock mass and in the drift. (b) Colored contours show matrix saturation; contour lines show vapor concentration (vapor mass fraction) in the matrix and in the drift. 
Figures 6 and 7 demonstrate clearly that in-drift natural convection strongly affects the TH conditions in the fractured rock mass at 500 years after emplacement. Below, we shall evaluate the flow and mass transport processes over the entire simulation period of 5,000 years. We may start with the in-drift conditions for Cases 1 and 2. Vapor concentration profiles along the drift are depicted in Figure 8 at different times during the postclosure period, extracted in a volume element just above the center of the drift. Three conclusions may be drawn: (1) Cases 1 and 2 show distinct differences not just at 500 years, as shown earlier, but at all times except at 5,000 years, when the vapor concentration along the drift is small in both cases. (2) The highest vapor content in the drift occurs at early heating stages, when boiling of pore water is most significant. (3) The vapor concentrations in the heated drift section remain elevated long after the rock mass has returned to below-boiling temperatures.

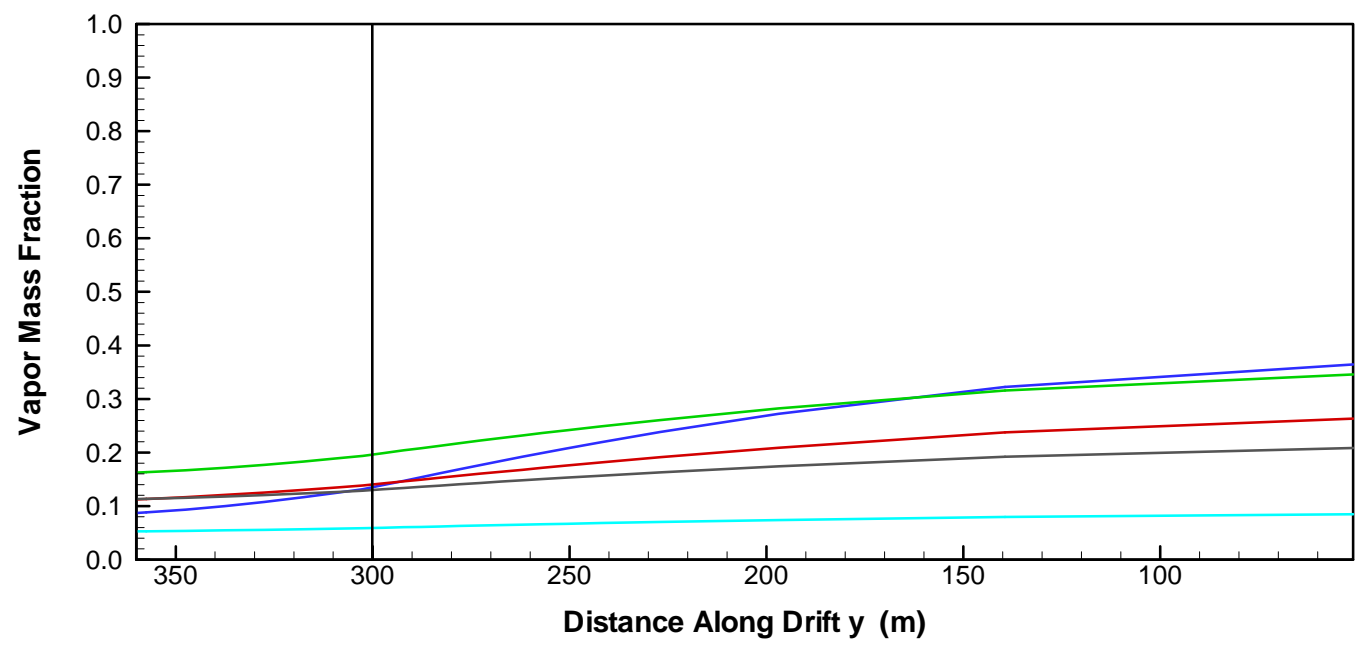

(a)

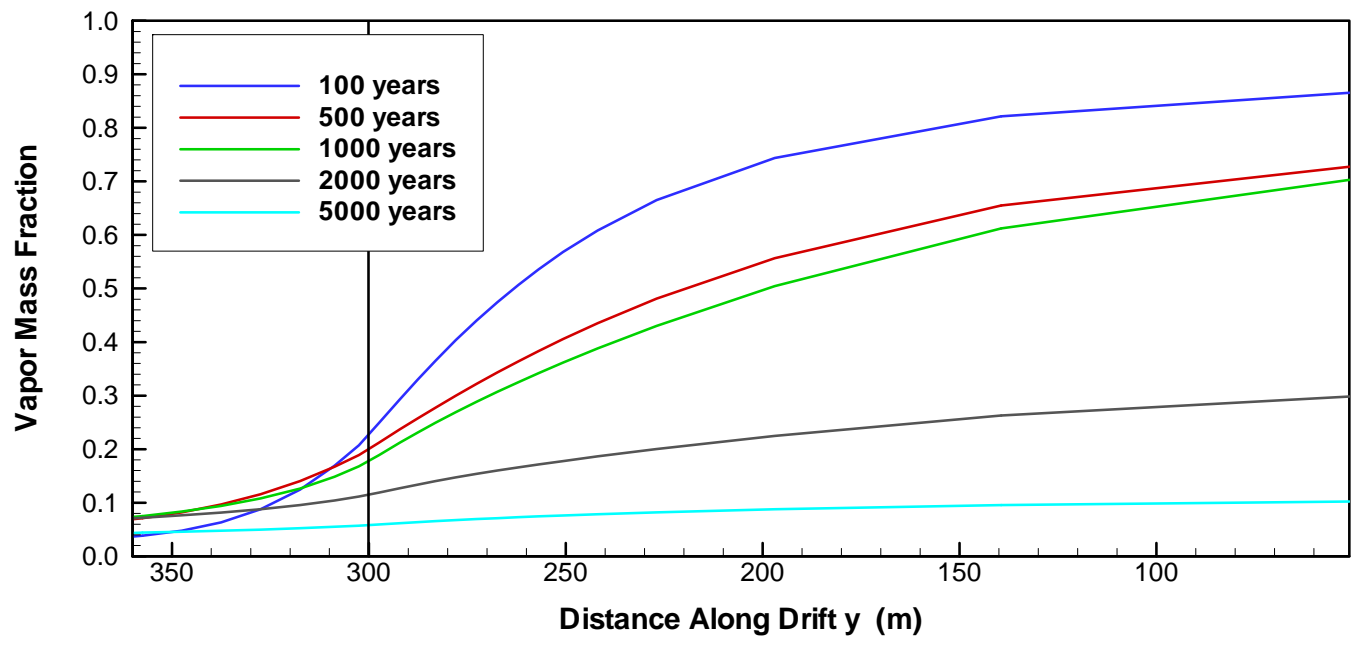

(b)

Figure 8. Vapor concentration along drift just above drift center for (a) Case 1 and (b) Case 2. 
While vapor concentration is a good indicator for the absolute moisture content in the gas phase, it does not convey the relation between the actual vapor pressure and the saturated vapor pressure, the latter being a function of the local temperature. In other words, vapor concentration alone does not indicate whether condensation may occur (or not) at the considered thermophysical conditions. We have therefore plotted profiles of relative humidity in Figure 9, for the same times and the same two simulation cases as in Figure 8. Relative humidity of less than $100 \%$ in the drift indicates that evaporation of pore water would occur in the adjacent fractured rock (provided that liquid water is present in the rock pores). Relative humidity equal to 100\%, on the other hand, implies that there is no evaporation, and that any vapor mass exceeding the corresponding vapor concentration would condense.

All relative humidity profiles in Figure 9 exhibit strong differences between the heated and unheated drift sections. In the heated section, relative humidity is below 100\% at all times, in both Cases 1 and 2. This means that no condensation can occur in the vicinity of waste canisters, and that evaporative conditions exist over the entire simulation period. (Be aware, however, that local heat output variation between individual waste packages, which could lead to localized condensation, has not been considered in this analysis.) In the unheated sections, on the other hand, relative humidity is at $100 \%$, which explains the strong condensation patterns observed in Figures 6 and 7. In general, the relative humidity values along the heated section are smaller for Case 1 compared to Case 2, a result of the more intense convective mixing between vapor-poor and vapor-rich drift sections. In Case 2, the relative humidity profiles at 1,000, 2,000, and 5,000 years show a local minimum at the end of the heated section, with relative humidity locally reduced. This suggests that convective mixing is not strong enough (i.e., that the turbulent circulation patterns are not large enough) to impact the entire emplacement drift; only those sections are affected during these late time periods that are relatively close to the unheated drift turnout.

The question arises, how would the in-drift moisture conditions compare to Case 3 where axial transport along the drift is neglected? Since Case 3 is modeled by removing all open drift elements from the simulation, information on the in-drift vapor distribution is not directly available from our simulation results. However, it is reasonable to assume that the in-drift vapor concentrations would be in close equilibrium with those in the adjacent fractured rock (because there is no axial transport driving vapor away). We have therefore plotted in Figure 10 the vapor 
concentration and relative humidity values extracted in the fractured rock just above the drift crown, at 500 years after emplacement for the three simulation cases. Both Cases 1 and 2 exhibit strongly reduced vapor concentration and relative humidity conditions compared with Case 3, indicating the importance of enhanced vapor transport even when moderate convective mixing is assumed. In Case 3, the relative humidity in the fractured rock (and thus in the drifts) is already at $100 \%$ over a $70 \mathrm{~m}$ section near the unheated end of the drift. This section corresponds to the section where the rock temperature has decreased below the boiling point (compare with Figure 5). In other words, without axial vapor transport, the rock and in-drift gas phase becomes vaporsaturated soon after boiling in the rock has ceased and the fractured rock has started to resaturate.

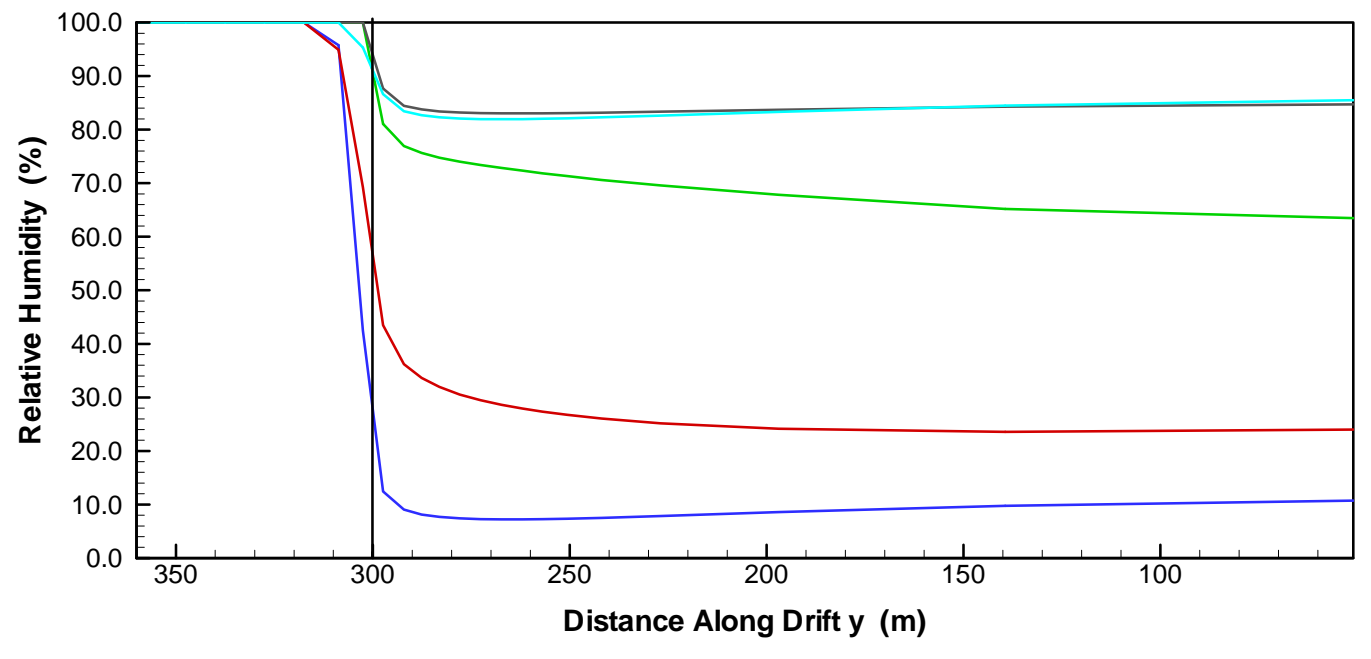

(a)

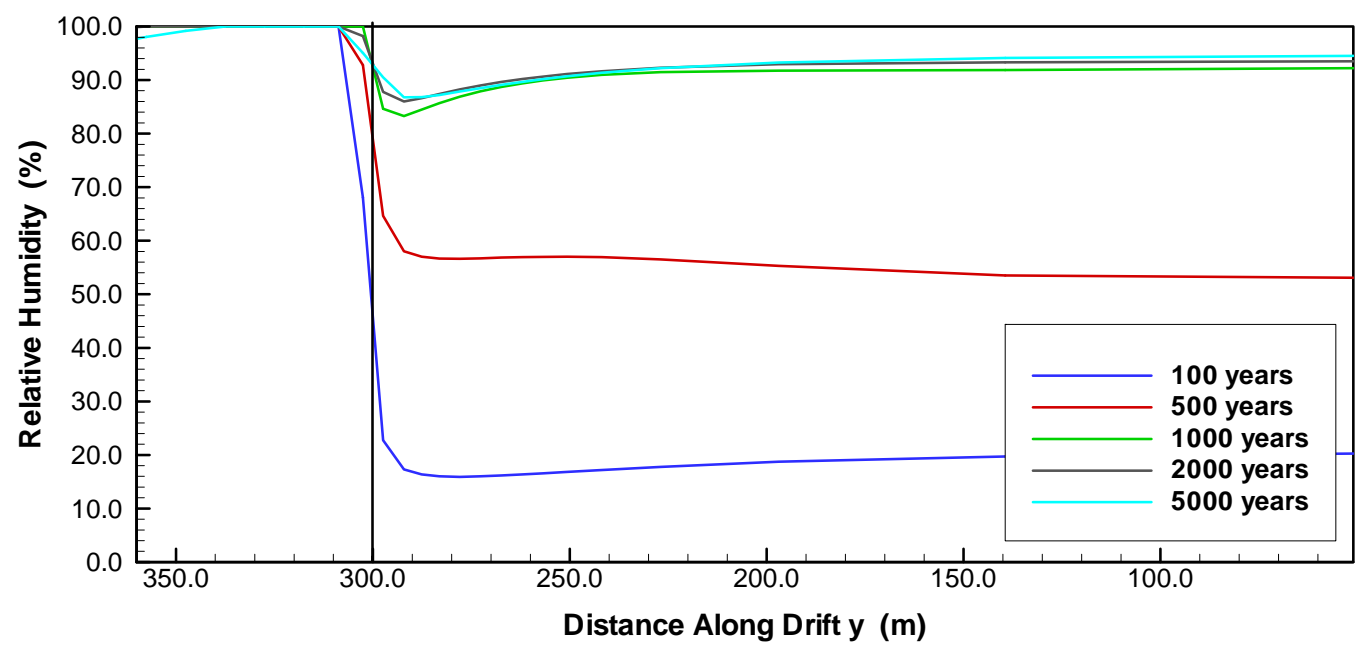

(b)

Figure 9. Relative humidity along drift just above drift center for (a) Case 1 and (b) Case 2. 


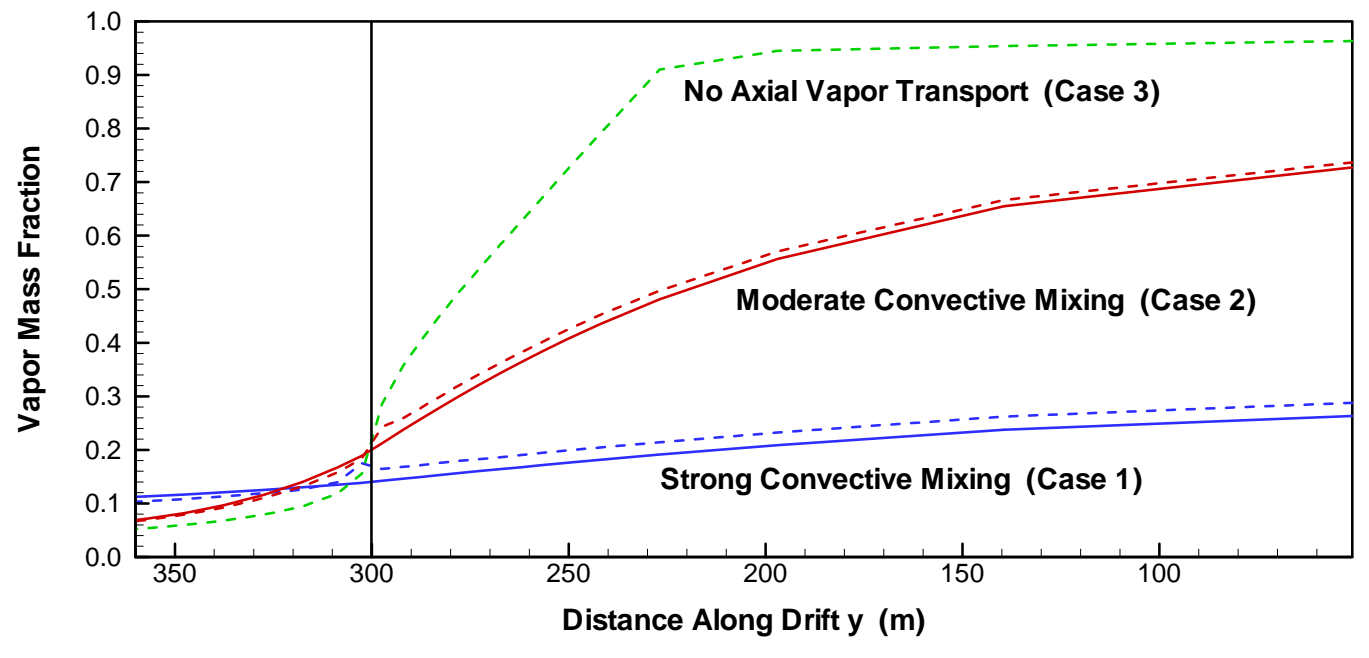

(a)

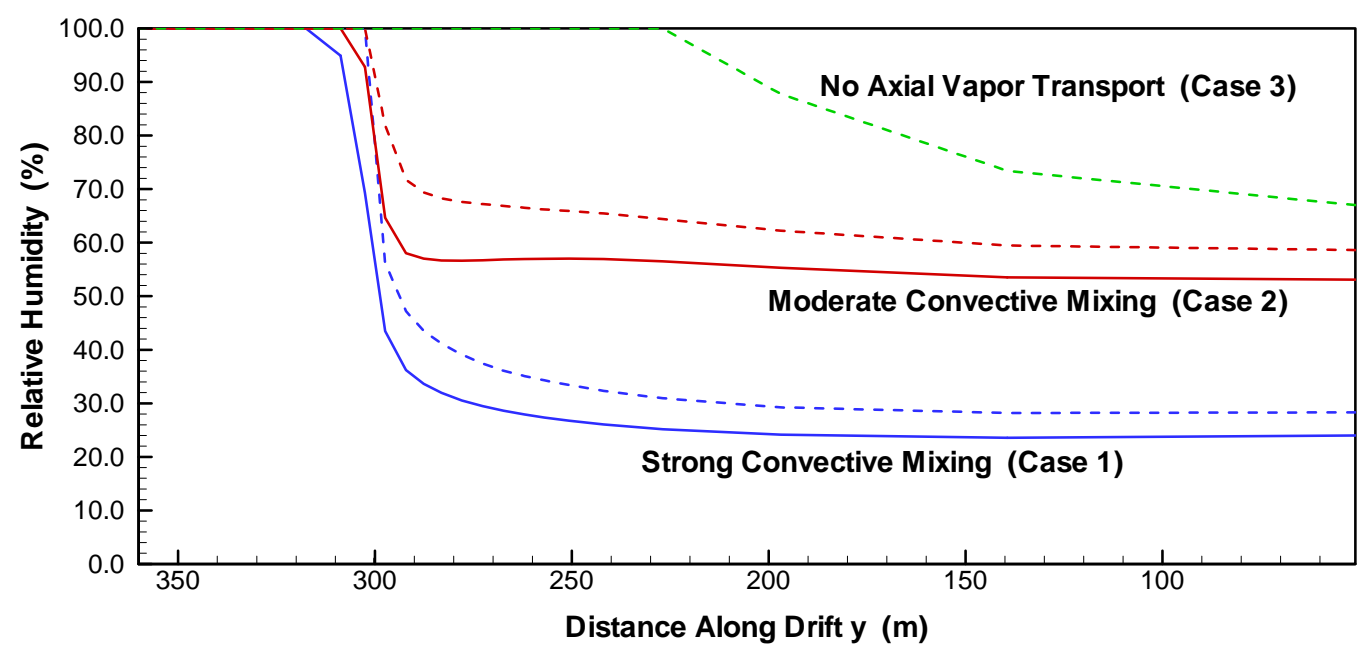

(b)

Figure 10. (a) Vapor mass fraction and (b) relative humidity along drift at 500 years after emplacement. Dashed lines give vapor mass fraction and relative humidity extracted in fracture element just above drift crown. For comparison with Figures 8 and 9, solid lines give in-drift conditions extracted just above drift center.

The evolution of the vapor mass transfer between the fractured rock and the drift integrated over the heated drift section is displayed in Figure 11. (Only Cases 1 and 2 are shown, since there is no vapor mass transfer in Case 3.) To allow for a direct comparison, the integrated vapor fluxes are given as relative values, divided by the total liquid flux arriving over the footprint of the heated drift section from ambient percolation. A relative vapor flux of one, for example, means that the vapor mass migrating from the formation into the drift is identical to the liquid mass arriving via percolation. (Note that the ambient percolation flux is stepwise adjusted in the simulation to account for expected climate changes at 600 years and 2,000 years. Accordingly, the percolation flux values used for calculating relative vapor fluxes are $6 \mathrm{~mm} / \mathrm{yr}$ for the time 
period from now to 600 years, $16 \mathrm{~mm} / \mathrm{yr}$ for 600 to 2000 years, and $25 \mathrm{~mm} / \mathrm{yr}$ thereafter.) The figure exemplifies the importance of the drift as a conduit for vapor transport out of the near-drift fractured rock, in particular in Case 1. At early heating stages, the amount of vapor transferred into the drift in Case 1 is almost 10 times higher than the water arrival from natural percolation, suggesting that the vapor source is mostly resident pore water. With time, the magnitude of vapor transfer reduces significantly, but not to negligible values. At 5,000 years, for example, more than $20 \%$ of the long-term percolation flux arriving at the drift is still being transferred into the drift by means of vapor transport. In Case 2, vapor transfer is clearly less effective, with relative values of about 5 at early times that reduce to negligible amounts after about 2,000 years.

In addition to the total vapor flux into the drift along the heated section, we also plotted the total liquid flux leaving the unheated end section of the drift into the fracture continuum. The total liquid fluxes leaving the drift into the fractures are slightly smaller than the total vapor fluxes entering the drift. This indicates that a small fraction of the vapor condensing in the unheated end unheated section is imbibed into the matrix pores, where the liquid remains mostly immobile because of the small matrix permeability (compare with Figure 6b and Figure $7 b$ ). However, the majority of the vapor drains off into the underlying formations.

Figure 11 furthermore distinguishes between convective and diffusive transport of vapor between the formation and the drift. Convective transport results from the pressure increase in the fractured rock as pore water boils off, while diffusive transport is caused by the vapor concentration gradient. In Case 1, diffusion is the dominant transport mechanism, since the strong mixing along the drift ensures small vapor concentrations and thus a large concentration gradient. In Case 2, vapor diffusion is less important, while the magnitude and evolution of convective transfer is comparable to Case 1. Thus, the differences between Case 1 and Case 2 are mostly a result of the more or less effective diffusive exchange. Note that in both cases, convective transport is only effective for the first 2,000 years after emplacement. 


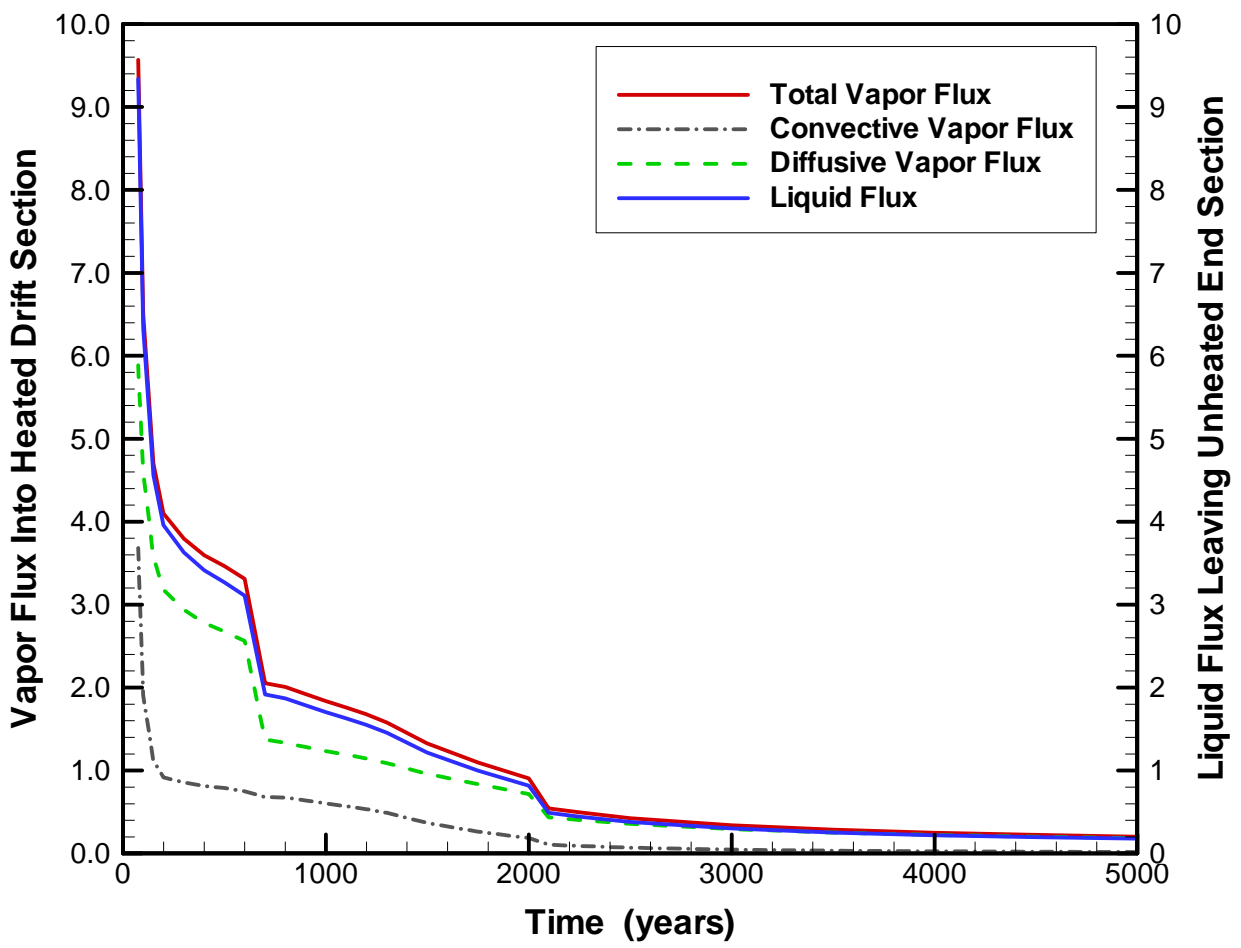

(a)

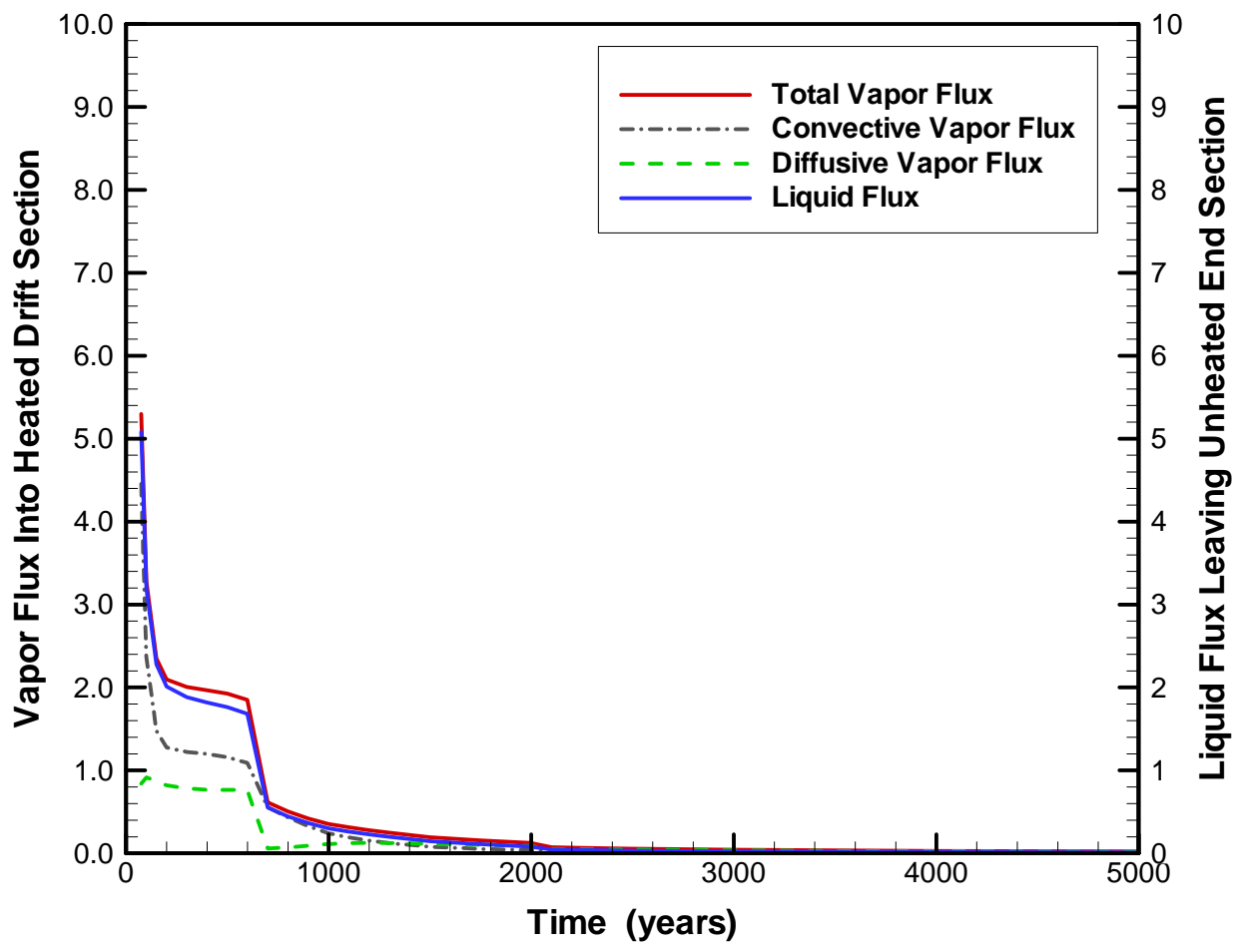

(b)

Figure 11. Evolution of vapor flux from formation to drift integrated over heated drift section for (a) Case 1 and (b) Case 2. Vapor flux is normalized by dividing with ambient percolation flux integrated over the cross-sectional area of the heated drift section. 
Let us now analyze in more detail how the observed in-drift conditions affect the thermalhydrological situation in the near-drift fractured rock. It is useful to plot the evolution of matrix liquid saturation along the drift for selected times (Figure 12), considering all three simulation cases. The figure shows clearly how important it is to account for in-drift transport in $\mathrm{TH}$ simulations of the rock mass at Yucca Mountain. In Case 3, with no vapor transfer between the formation and the drift, the rock mass near the drift resaturates much earlier after the initial dryout and arrives at much higher long-term saturation levels along the emplacement section. These observations are particularly apparent in comparison with Case 1. At 500 years, for example, the matrix pores along the emplacement section are still desaturated in Case 1, while Case 3 already exhibits considerable saturation buildup. Further, in Case 1 the maximum saturation at 5,000 years is less than 0.7 , indicating that evaporation remains effective, while Cases 2 and 3 end up with maximum saturations of 0.94 and 0.97, respectively. Notice the local minimum in the saturation profiles of Case 2 at 1,000, 2,000, and 5,000 years, which corresponds to a similar minimum in the relative humidity profiles in Figure 9b. Convective mixing reduces the moisture content in the rock matrix, but only over a limited drift length close to the end of the heated section.

The volumetric evolution of rock dryout as a function of time is presented in Figure 13. Rock dryout estimates have been derived by adding the volume of all mesh elements along the heated drift section that have a matrix saturation less than 0.425 (i.e., half of the initial matrix saturation). In Case 1, the total dryout volume calculated from this procedure is as high as 37,000 $\mathrm{m}^{3}$, which translates into an average circular extent of about $6.5 \mathrm{~m}$ dry rock from the drift walls. (Note that the volumetric values are given for a half-drift model with $300 \mathrm{~m}$ emplacement length. Values need to be quadrupled for an entire full drift emplacement section with $600 \mathrm{~m}$ length.) The maximum value in Case 2 is almost as large as in Case 1 at early heating stages, but the dry rock volume decreases much faster with time. Significantly less drying can be seen in Case 3, where the maximum volume is on the order of $25,000 \mathrm{~m}^{3}$, about $65 \%$ of Case 1.

It is of interested to determine how these changes in TH conditions affect the heat-related perturbation of liquid fluxes in the fractured rock. Figure 14 shows the downward liquid fluxes at different times along a horizontal profile chosen close to the center of the heated drift section. The profile is perpendicular to the drift axis (x-direction); it starts at the sidewall of the drift and extends laterally several meters into the fractured rock. All fluxes are given relative to the 
ambient natural percolation flux at the considered time; i.e.; fluxes larger than one denote a flux enhancement. At early heating stages (i.e., 100 and 500 years), vaporization of pore water and subsequent condensation lead to a considerable flux elevation just outside of the dryout zone where the condensate drains off. Note the strong differences between the different simulation cases, with Case 1 showing much less flux elevation than the other cases because more vapor moves out of the fractured rock into the drift. Flux elevation during boiling is a concern for repository performance, because it may increase the potential for preferential flow events penetrating the dryout region and possibly dripping into the heated drift (Birkholzer and Ho, 2003; Birkholzer et al., 2003). Later, when boiling has ceased and the fracture rock near the drift resaturates, the maximum vertical fluxes occur close at the drift wall. These fluxes are enhanced because water-arriving at the drift crown from natural percolation-is diverted sideways and around the drift as a result of the capillary barrier at the drift wall. Again, the flux elevation is smallest in Case 1, since liquid water present near the drifts is subject to evaporation. Compared to the other cases, strong desaturation can be seen at 1,000 and at 2,000 years in Case 1; less pronounced is the impact of evaporation at 5,000 years. These results correlate well with the evolution of the vapor transfer between the fractured rock and the drift. 


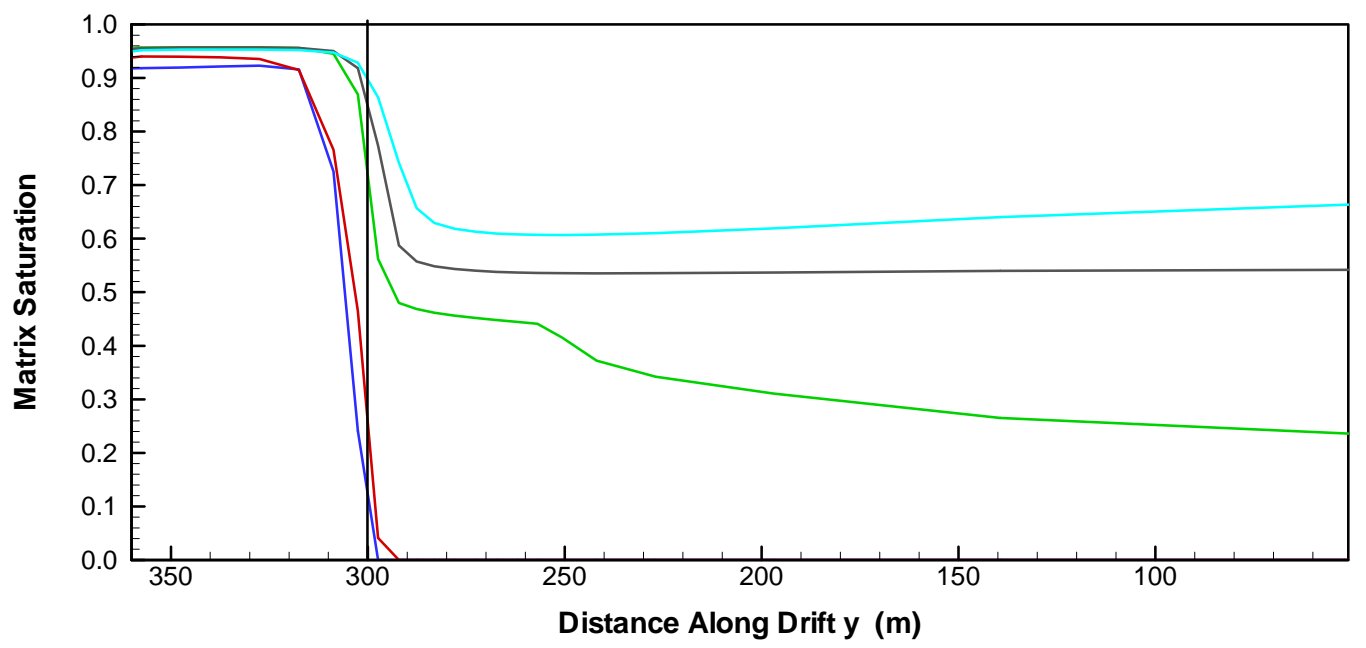

(a)

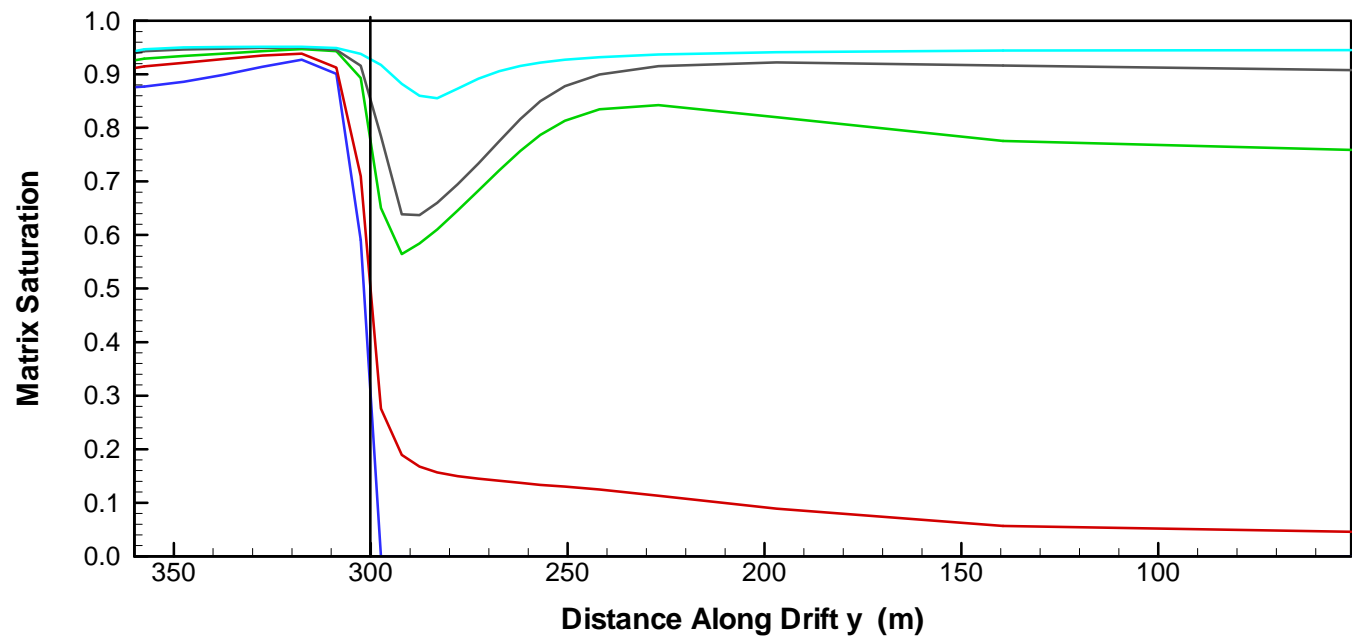

(b)

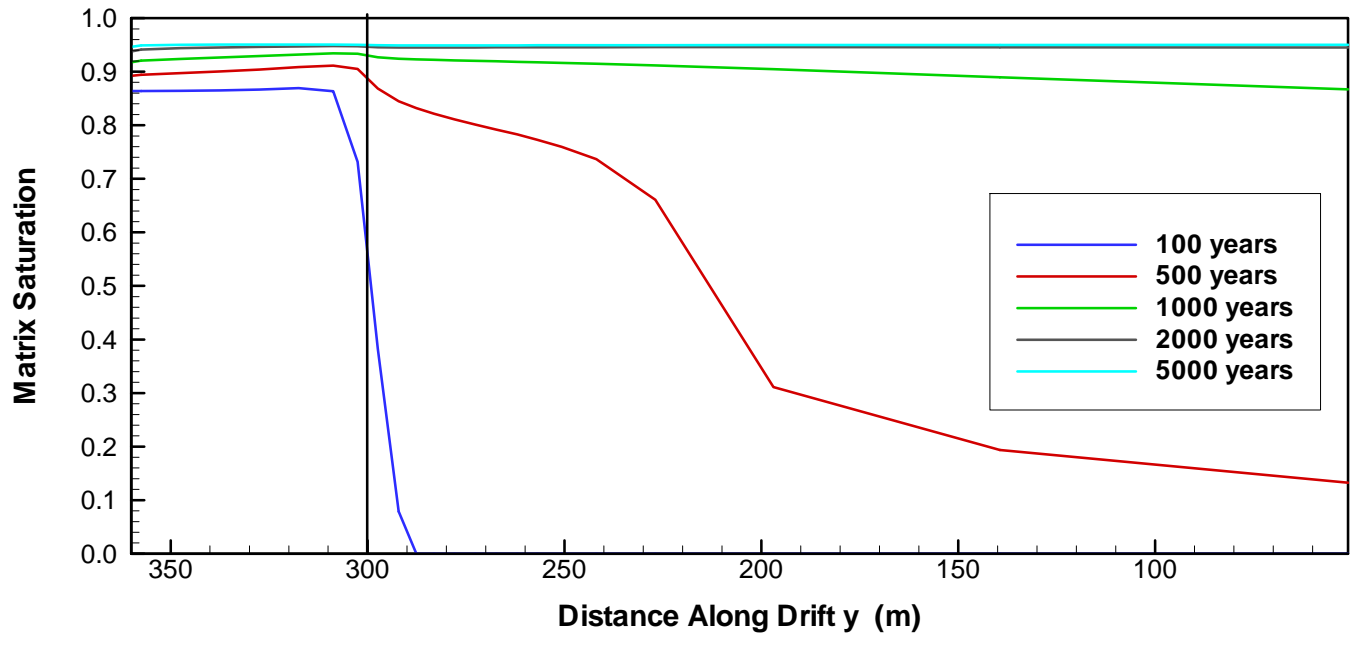

(c)

Figure 12. Matrix saturation along drift just above drift crown for (a) Case 1, (b) Case 2, and (c) Case 3 


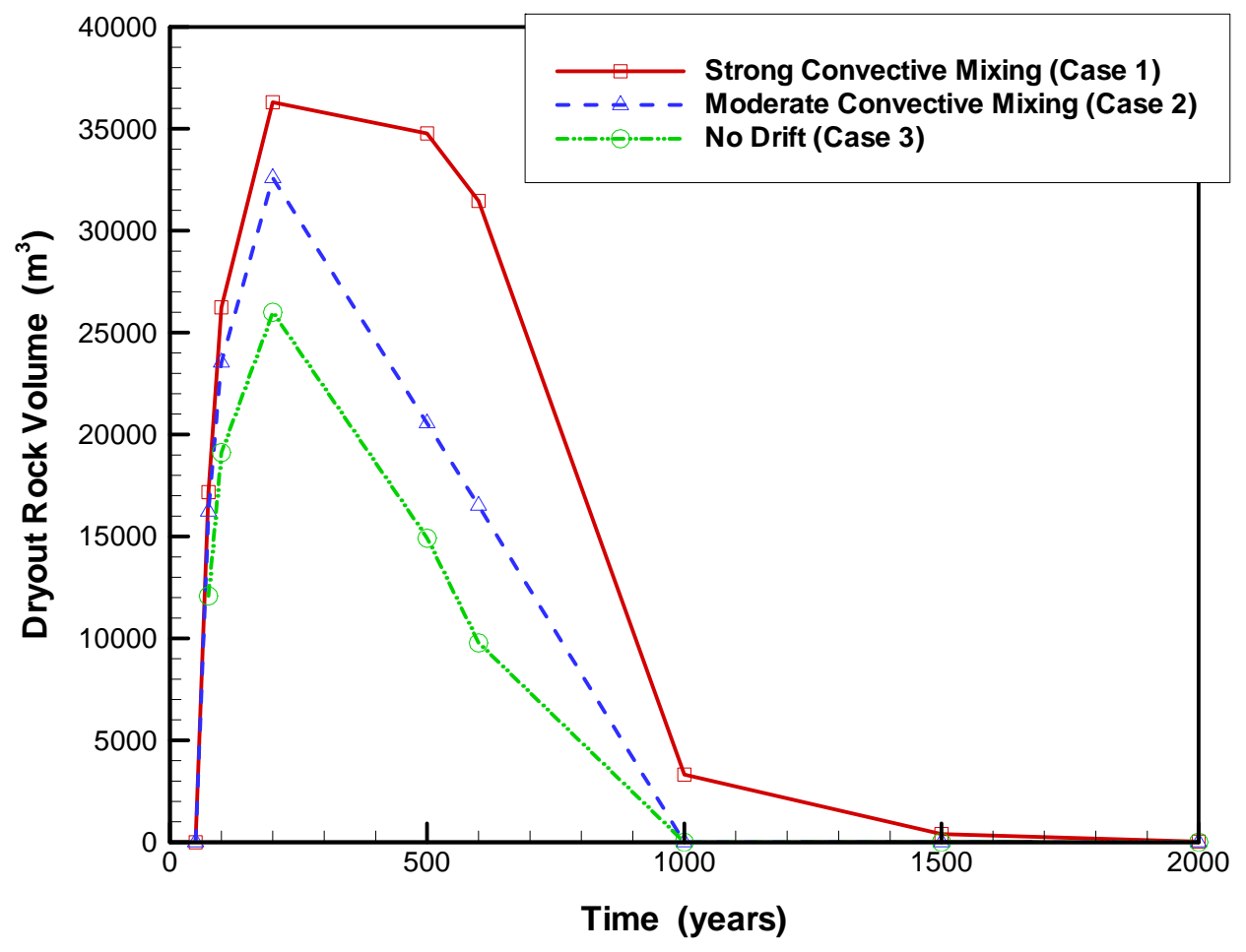

Figure 13. Evolution of dryout volume of rock mass along heated drift section. Threshold used for dryout is a matrix saturation less than 0.425 , half of the average ambient saturation. 

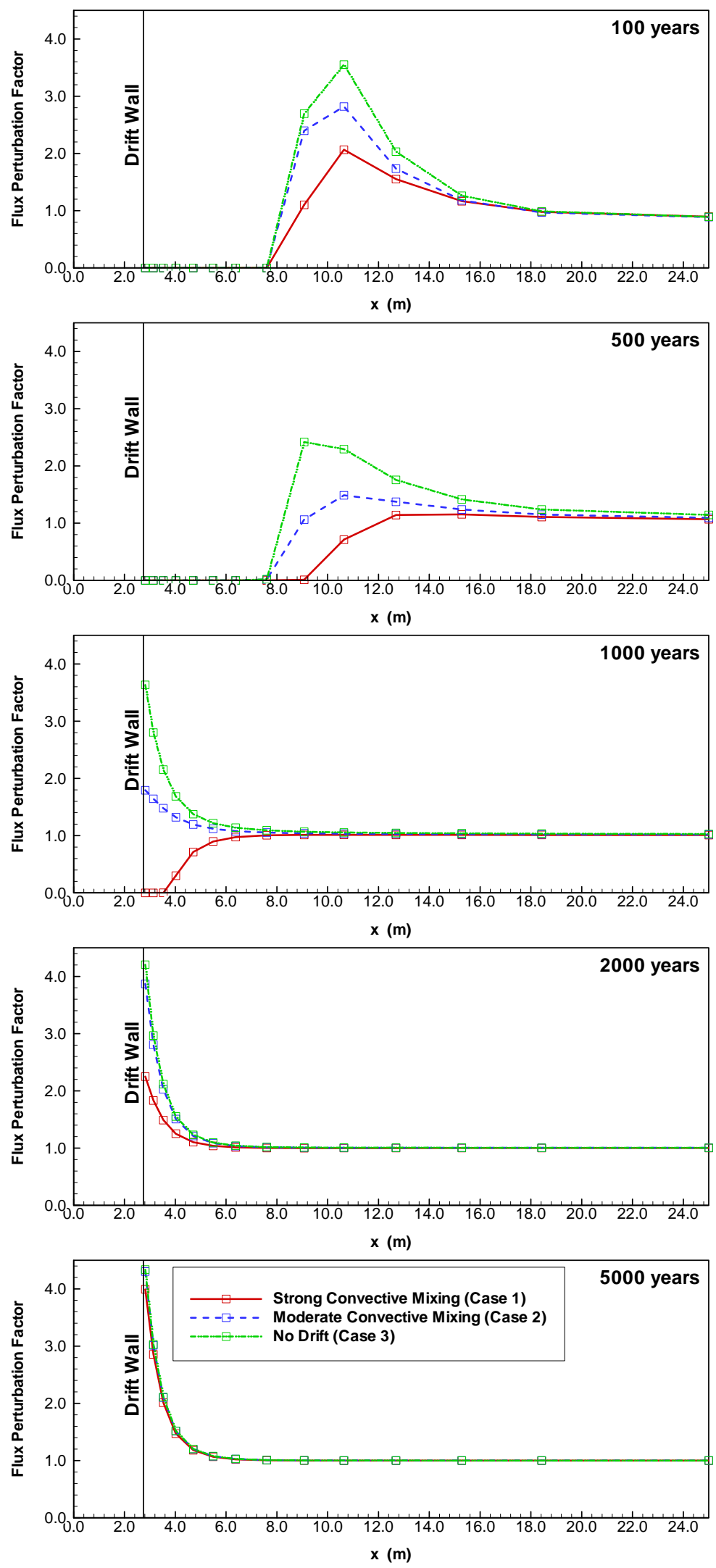

Figure 14. Vertical liquid fluxes in horizontal profile from drift wall into fractured rock in a drift section close to the center of the drift. Fracture and matrix fluxes have been summed up and divided by ambient percolation flux at the considered time. 


\section{SUMMARY AND CONCLUSIONS}

We have conducted a numerical study to evaluate how the axial vapor transport caused by natural convection in waste emplacement drifts will affect the TH conditions in the surrounding fractured rock during the postclosure period at Yucca Mountain. A new simulation method was developed that couples existing model approaches for predicting heat and mass transport in the rock mass with modules that approximate turbulent mixing in drifts. Following Webb and Itamura (2004), in-drift convection is represented as a binary diffusion process, with effective dispersion coefficients directly calculated from supporting CFD analyses. Mass and heat transfer between the formation and the drift are estimated from empirical boundary-layer correlations, based on a methodology developed in Webb and Reed (2004). The governing equations for the integrated drift and rock mass models are solved in a fully coupled, noniterative manner, ensuring consistency between the TH conditions in the fractured rock and those in the open drift.

The new model was applied to simulate the first 5,000 years after waste emplacement in a three-dimensional model domain comprising a representative waste emplacement drift and the surrounding rock mass. Three main simulation cases were conducted. The first two cases use different sets of effective dispersion coefficients, covering the possible range of convective conditions in drifts. For comparison, the third case ignores the presence of the drifts as an open conduit for heat and vapor transport.

Our simulation results demonstrate the significance of in-drift natural convection on the TH conditions in the fractured rock. Natural convection causes the transport of vapor-rich gases from the heated emplacement sections towards the cooler drift end sections, where the vapor condenses and drains off into underlying rock formations. At the same time, vapor-poor gases circulate back towards the emplacement sections of the drift, thereby reducing the vapor concentration and the relative humidity in these areas. As a result, vapor is effectively driven out of the heated rock mass and into the open drifts. These processes are particularly strong during the early heating stages, when temperatures are high enough to cause boiling of pore water, but remain important as long as moderate temperature differences occur between the heated and the unheated drift sections. Compared to the simulation case neglecting the drift, natural convection causes (1) a larger rock dryout region during the boiling period, (2) a later resaturation of the near-drift rock mass and a smaller long-term saturation value, (3) less moisture redistribution within the fractured rock from boiling and condensation, and (4) less heat-induced flux 
perturbation. These results are generally expected to improve the performance of the repository, since less flux perturbation and smaller relative humidity values form a more desirable waste package environment.

There are significant differences between the two simulation cases with different effective dispersion coefficients, representing strong versus moderate convective mixing. The first case shows a much more pronounced reduction of the moisture content in the drift and the rock mass over a longer duration. As mentioned before, the two sets of effective dispersion coefficients were determined by Webb and Itamura (2004) as first-order estimates for the possible range of in-drift natural convection. Considering the significant sensitivity observed in our results, additional CFD modeling work and scaled laboratory experiments would be beneficial to better constrain the degree of turbulent circulation in Yucca Mountain emplacement drifts.

While the results of our study have demonstrated the importance of natural convection in assessing the future TH conditions in the fractured rock mass at Yucca Mountain, it is important to consider that we have employed some limiting model assumptions for the in-drift heat and mass transport. Among these are the approximation of in-drift flow patterns as a diffusive mixing process, the geometric simplification of the waste package and the drip shield as one lumped entity, and the assumption of a uniform heat load which averages the heat output variability of individual waste packages. As a result, the model does not predict small-scale patterns of relative humidity conditions and local condensation effects within the heated drift, while the overall degree of heat and moisture transport along the open drifts is well represented. The latter is most important for assessing the impact of natural convection on the future TH conditions in the fractured rock mass at Yucca Mountain. 


\section{ACKNOWLEDGMENT}

This work was supported by the Director, Office of Civilian Radioactive Waste Management, Office of Science and Technology and International, of the U.S. Department of Energy. Review and comments of Matthew Reagan and Dan Hawkes from Berkeley Lab are greatly appreciated.

\section{REFERENCES}

Birkholzer, J.T., C.K. Ho, A Probabilistic Analysis of Episodic Preferential Flow into Superheated Fractured Rock, Journal of Hydrology, 284, 151-173, 2003.

Birkholzer, J.T., S. Mukhopadhyay, Y.W. Tsang, The Impact of Preferential Flow on the Vaporization Barrier Above Waste Emplacement Drifts at Yucca Mountain, Nevada, Nuclear Technology, 148, 138-150, 2003.

Birkholzer, J.T., S. Mukhopadhyay, Y.W. Tsang, Modeling Seepage into Heated Waste Emplacement Tunnels in Unsaturated Fractured Rock, Vadose Zone Journal, 3, 819-836, 2004.

Bodvarsson, G.S., W. Boyle, R. Patterson, D. Williams, Overview of Scientific Investigations at Yucca Mountain-The Potential Repository for High-Level Nuclear Waste, Journal of Contaminant Hydrology, 38(1-3), 3-24, 1999.

BSC (Bechtel SAIC Company), Repository Design Project, RDP/PA IED Typical Waste package Components Assembly (3), 800-IED-WIS0-00203-000-00A, Las Vegas, NE, Bechtel SAIC Company, 2003.

Buscheck, T.A., N.D. Rosenberg, J. Gansemer, Y. Sun, Thermohydrologic Behavior at an Underground Nuclear Waste Repository, Water Resources Research, 38(3), 1-19, 2002.

Dalvit-Dunn, S., S.W. Webb, N.D. Francis, M.T. Itamura, J. Del Mar, Comparison of CFD Calculations with Experimental Results for the YMP Scaled Natural Convection Tests, Proceedings of 2004 ASME Heat Transfer/Fluids Engineering Summer Conference, Charlotte, NC, June 11-15, 2004.

Danko, G., D. Bahrami, Powered and Natural Passive Ventilation at Yucca Mountain, Proceedings of the International High-Level Radioactive Waste Management Conference, Las Vegas, NE, March 30-April 2, 2003. 
Danko, G., D. Bahrami, Heat and Moisture Flow Simulation with MULTIFLUX, Proceedings of 2004 ASME Heat Transfer/Fluids Engineering Summer Conference, Charlotte, NC, June 1115, 2004.

Doughty, C., Investigation of Conceptual and Numerical Approaches for Evaluating Moisture, Gas, Chemical, and Heat Transport in Fractured Unsaturated Rock, Journal of Contaminant Hydrology, 38(1-3), 69-106, 1999.

Ghezzehei, T.A. R.C. Trautz, S. Finsterle, P.J. Cook, C.F. Ahlers, Modeling Coupled Evaporation and Seepage in Ventilated Cavities, Vadose Zone Journal, 3, 806-818, 2004.

Ghezzehei, T., H.H. Liu, Calibrated Properties Model, MDL-NBS-HS-000003 REV 02, Las Vegas, NE, Bechtel SAIC Company, 2004.

Haukwa, C.B., Y.-S. Wu, G.S. Bodvarsson, Thermal Loading Studies Using the Yucca Mountain Unsaturated Zone Model, Journal of Contaminant Hydrology, 38 (1-3), 217-255, 1999.

Haukwa, C.B., Y.W. Tsang, Y.-S. Wu, G.S. Bodvarsson, Effect of Heterogeneity on the Potential for Liquid Seepage into Heated Emplacement Drifts of the Potential Repository, Journal of Contaminant Hydrology, 62-63, 509-527, 2003.

Incropera, F.P., D.P. DeWitt, Introduction to Heat Transfer, John Wiley \& Sons, New York, Fourth Edition, 2002.

Kuehn, T.H., R.J. Goldstein, Correlating Equations for Natural Convection Heat Transfer in Between Horizontal Circular Cylinders, International Journal of Heat and Mass Transfer, 19, 1127-1134, 1976.

Kuehn, T.H., R.J. Goldstein, An Experimental Study of Natural Convection Heat Transfer in Concentric and Eccentric Horizontal Cylindrical Annuli, Journal of Heat Transfer, 100, 635640, 1978.

Liu, H.H., C. Doughty, G.S. Bodvarsson, An Active Fracture Model for Unsaturated Flow and Transport in Fractured Rocks, Water Resources Research, 34(10), 2633-2646, 1998.

Mukhophadhyay, S., Y.W. Tsang, Understanding the Anomalous Temperature Data from the Large Block Test at Yucca Mountain, Nevada, Water Resources Research, 38(10), 28-1 through 28-12, 2002.

Pruess, K., TOUGH User’s Guide, NUREG/CR-4645, Washington, D.C., U.S. Nuclear Regulatory Commission, 1987. 
Pruess, K., J.S.Y. Tsang, Y.W. Tsang, On Thermohydrologic Conditions Near High-Level Nuclear Wastes Emplaced in Partially Saturated Fractured Tuff: 1. Simulation Studies with Explicit Consideration of Facture Effects, Water Resources Research, 26, 1235-1248, 1990a.

Pruess, K., J.S.Y. Tsang, Y.W. Tsang, On Thermohydrologic Conditions Near High-Level Nuclear Wastes Emplaced in Partially Saturated Fractured Tuff: 2. Effective Continuum Approximations, Water Resources Research, 26, 1249-1261, $1990 \mathrm{~b}$.

Pruess, K., C. Oldenburg, G. Moridis, TOUGH2 User’s Guide, Version 2.0, LBNL-43134, Berkeley, California, Lawrence Berkeley National Laboratory, 1999.

Raithby, G.D., K.G.T. Hollands, Natural Convection, Chapter 6 of Handbook of Heat Transfer Fundamentals, McGraw-Hill Book Company, New York, Second Edition, 1985.

Siegel, R., J.R. Howell, Thermal Radiation Heat Transfer, McGraw-Hill Book Company, New York, 1972.

Spycher, N.F., E.L. Sonnenthal, J.A. Apps, Fluid Flow and Reactive Transport Around Nuclear Waste Emplacement Tunnels at Yucca Mountain, Nevada, Journal of Contaminant Hydrology, 62-63, 653-673, 2003.

Tsang, Y.W., J.T. Birkholzer, Predictions and Observations of the Thermal-Hydrologic Conditions in the Single Heater Test, Journal of Contaminant Hydrology, 38(1-3), 395-426, 1999.

van Genuchten, M.T., A Closed-Form Equation for Predicting the Hydraulic Conductivity of Unsaturated Soils, Soil Science Society of America Journal, 44, 892-898, 1980.

Walsh, R., V. Chipman, J. Del Mar, Y. Sun, J. Case, Ventilation Model and Analysis Report, ANL-EBS-MD-000030 REV 04, Las Vegas, NE, Bechtel SAIC Company, 2004.

Webb, S.W., and M.T. Itamura, Calculation of Post-Closure Natural Convection Heat and Mass Transfer in Yucca Mountain Drifts, Proceedings of 2004 ASME Heat Transfer/Fluids Engineering Summer Conference, Charlotte, NC, June 11-15, 2004.

Webb, S.W., and A. Reed, In-Drift Natural Convection and Condensation, MDL-EBS-MD00001 REV 00, Yucca Mountain Project Report, Bechtel SAIC Company, Las Vegas, NE, 2004.

Webb, S.W, N.D. Francis, S. Dalvit-Dunn, M.T. Itamura, and D.L. James, Thermally-Induced Natural Convection Effects in Yucca Mountain Drifts, Journal of Contaminant Hydrology, 62-63, 713-730, 2003. 